\title{
Evolutionary Game Analysis of Three Players on Behavioural Strategy of P2P Lending Participants: A Sustainable Operations Perspective
}

\author{
Ge You, ${ }^{1,2}$ Hao Guo $\mathbb{D}^{3},{ }^{3}$ Abd Alwahed Dagestani $\mathbb{D}^{,},{ }^{4}$ and Shuai Deng ${ }^{5}$ \\ ${ }^{1}$ School of Management, Jinan University, Guangzhou 510632, China \\ ${ }^{2}$ Nanfang College.Guangzhou, Guangzhou 510970, China \\ ${ }^{3}$ School of Management, Wuhan Textile University, Wuhan 430200, China \\ ${ }^{4}$ School of Business, Central South University, Changsha 410083, China \\ ${ }^{5}$ School of Economics and Management, Hunan Institute of Technology, Hengyang 421001, China \\ Correspondence should be addressed to Hao Guo; haoguo8701@gmail.com and Abd Alwahed Dagestani; \\ a.a.dagestani@csu.edu.cn
}

Received 3 May 2021; Revised 2 August 2021; Accepted 11 August 2021; Published 18 August 2021

Academic Editor: Baogui Xin

Copyright $\odot 2021 \mathrm{Ge}$ You et al. This is an open access article distributed under the Creative Commons Attribution License, which permits unrestricted use, distribution, and reproduction in any medium, provided the original work is properly cited.

In China, most of peer-to-peer (P2P) lending platforms do not possess operational sustainability due to excessive defaults. To address this problem, the conflict of interests among P2P lending participants is discussed using a stakeholder approach. An evolutionary game model (EGM) of three players is developed to analyse the interactions among regulatory authorities, $\mathrm{P} 2 \mathrm{P}$ lending platforms, and borrowers. Then, the asymptotic of the equilibrium and evolutionary stability strategies of the EGM are analysed. Results indicate that either the P2P lending platforms or borrowers will choose "noncompliant operation" or "default" strategies from a short-term perspective, and the strict supervision of the P2P lending platform in the short term is necessary for the sustainable operation of the platform. When supervision is intensified in the early stage and regulatory pressure becomes a normal state, $\mathrm{P} 2 \mathrm{P}$ lending platforms and borrowers will actively select "compliant operation" and "repayment" strategies even if there is a lack of regulation in the future. Meanwhile, the behavioural strategies of $\mathrm{P} 2 \mathrm{P}$ lending participants can be changed to conform to the sustainability of P2P lending by reducing the costs of strict supervision and increasing the damage caused by general supervision, reward and punishment coefficient for P2P lending platforms, repayment incentives of borrowers, and defaulting opportunity costs. Finally, suggestions for regulating the behaviours of P2P lending participants and promoting sustainability of P2P lending industry are discussed.

\section{Introduction}

Peer-to-peer (P2P) lending, as a supplement to the modern financial system, deals with the financing difficulties for small and medium-sized enterprises (SMEs). It plays an important role in promoting inclusive finance [1]. The number of $\mathrm{P} 2 \mathrm{P}$ lending platforms has increased significantly in many countries. In China, the P2P lending industry has increased 60 times from 2013 to 2017 [2]. However, P2P lending has been increasingly regulated in recent years [3], and most of P2P lending platforms do not possess operational sustainability due to the excessive defaults. By the beginning of 2021, the number of normal operational P2P lending platforms was only six in China, more than 6000 platforms have gone bankrupt, and the transaction volume of the P2P lending has dropped by nearly $80 \%$ compared with the peak in 2017 [4]. That is to say, the sustainability issue of the P2P lending industry is becoming a challenge of the P2P lending in China. In this context, it is significant to understand the interests and interactions of the P2P lending stakeholders. In practice, most of the $\mathrm{P} 2 \mathrm{P}$ lending platforms cannot coordinate the interests of $\mathrm{P} 2 \mathrm{P}$ participants to ensure the sustainable operation of $\mathrm{P} 2 \mathrm{P}$ lending. Therefore, it is an important and interesting topic to focus on the behaviours and interactions of $\mathrm{P} 2 \mathrm{P}$ lending stakeholders from a sustainable operation perspective. 
More specifically, P2P lending includes many stakeholders, where regulatory authorities, P2P lending platforms, and borrowers are considered to be the three critical P2P lending participants $[5,6]$. The three participants often face a conflict of interest when pursuing their maximum interests, respectively. For example, in the case of weak regulation, P2P lending platforms can often obtain some extra benefits through noncompliant operations. Meanwhile, the total return of the society will become smaller, which is not aligned with the regulatory expected revenue and damages the interests of regulatory authorities. According to García-Pérez et al. [7] and Cao et al. [8], sustainability can be seen as the result of the coordination of interests among multiple stakeholders. It is almost impossible to achieve the sustainable operation of P2P lending if the conflict of interest among P2P lending participants is not balanced [9]. Besides, due to a lack of legal and regulatory systems of the P2P lending [10], inadequate regulatory basis [11], and high regulatory costs and rent-seeking behaviour [12], the regulation of P2P lending market usually receives a great uncertainty. Therefore, the sustainable operation of the P2P lending market depends on the strategic game among the regulations by regulatory authorities, compliant behaviours of $\mathrm{P} 2 \mathrm{P}$ lending platforms, and repayment behaviours of borrowers.

In recent years, issues about the behaviour of P2P lending participants have received increasing attention, but it is still in its early stages. First, most researchers are keen to study the herding behaviour in the P2P [13-15], defaulting behaviour of borrowers in P2P lending $[16,17]$, and operational behaviour of P2P lending platforms [18]. These studies generally focus on the characteristic and influencing factors of the behaviour of a single participant, but the interactions with each other of P2P lending participants with regard to the operations are ignored. This evokes an interesting question on how behaviours of $\mathrm{P} 2 \mathrm{P}$ lending participants affect the sustainability of the P2P lending. Second, the researches on the interest coordination among the P2P lending participants are still limited in the previous literature. For instance, the interest-coordination mechanisms between multiple participants, such as lenders and platform [19], borrowers and lenders [20], and platforms and government $[12,21]$, are generally studied. However, the interest-coordination mechanisms are only for two players and cannot illustrate how to perform well for P2P lending participants to achieve sustainability of the $\mathrm{P} 2 \mathrm{P}$ lending industry. Third, from the perspective of sustainable operations, it is necessary to coordinate the interest of each $\mathrm{P} 2 \mathrm{P}$ lending participant and ensure that the participants can be profitable. For analysing the conflict of interest, an evolutionary game model (EGM) emphasizing bounded rationality and dynamic decision-making processes was formulated to study the interest-coordination mechanism among P2P lending participants. On the one hand, due to incomplete information and information asymmetry [20], regulatory authorities, P2P lending platforms, and borrowers fail to acknowledge the decision of each other (e.g., compliant operation or noncompliant operation, repayment, or default), and they show bounded rationality to make their decision according to the previous interactions among them. On the other hand, since the returns and costs vary in different games among regulatory authorities, P2P platforms, and borrowers, each participant will continuously change their strategies in the decision-making system. For example, regulatory authorities enhance the regulations because of the increasing returns, while the regulations are reduced by the growth of costs [22]. Similarly, borrowers adopt repayment strategy owing to rewards from the platforms [23], while they change the decision of repayment into default because of the reduction of defaulting cost. Thus, the behavioural system among regulatory authorities, P2P platforms, and borrowers should be captured by dynamic decision-making processes using the EGM. It is important and interesting to investigate the dynamical decisionmaking processes by using EGM.

According to an overview of the studies on the behaviour of the P2P lending participants, the research questions and openings that motivate this research are summarized as follows.

(i) What is the conflict of interest among regulatory authorities, P2P lending platforms, and borrowers? How to formulate and solve an EGM of three-player to balance the interests of the three participants?

(ii) How do behavioural strategies of P2P lending participants affect the evolutionary results? What are the optimal behaviour strategies for regulatory authorities, P2P lending platforms, and borrowers from the perspective of sustainable operations?

(iii) What is the impact of the relevant parameters on behavioural strategies of the three P2P lending participants?

To address the aforementioned issues, by adopting stakeholder approach, the conflicts of interest among regulatory authorities, P2P lending platforms, and borrowers are analysed in this paper. Besides, due to the asymmetric information available, short-sightedness, and self-interest [24, 25], P2P lending participants may show bounded rationality in multistage games. An EGM is developed, and the asymptotic of the equilibrium and evolutionary stability strategies of the EGM are analysed. Meanwhile, the interactions and the interest-coordination mechanisms among P2P lending participants are analysed.

The contributions include the following three points. (1) An EGM of three players is developed to explore interactions among regulatory authorities, $\mathrm{P} 2 \mathrm{P}$ lending platforms, and borrowers, which overcomes the limitations of two-player evolutionary game mechanism in previous studies. (2) The interest-coordination mechanism among $\mathrm{P} 2 \mathrm{P}$ lending participants is designed to guide each participant to choose the behavioural strategy, which is beneficial to the sustainability of P2P lending. The behavioural strategies of P2P lending participants are theoretically and numerically analysed, and the conclusions contributing to the sustainability of P2P lending are obtained. For instance, we find that the strict supervision of the $\mathrm{P} 2 \mathrm{P}$ platform in the short term is necessary for the sustainable operation of the platform. (3) We 
investigate the influencing factors of the behaviours and interactions of P2P lending participants systematically and analyse the impact of rewards and penalties by regulatory authorities, repayment incentives, and defaulting opportunity costs on the evolutionary stability strategies, and we propose suggestions for sustainable development of the P2P lending industry.

The rest of this paper is organized as follows: Section 2 reviews the existing literature concerning the behaviour of P2P lending participants, conflict of interest among P2P lending stakeholders, and evolutionary game theory. In Sections 3 and 4, an EGM of three-player is proposed to analyse the interactions among regulatory authorities, P2P lending platforms, and borrowers. Section 5 presents the numerical study and discusses the computational results. Section 6 provides conclusion and directions for future research.

\section{Related Work}

In recent years, many scholars have paid attention to study the P2P lending. In line with the title and structure of this paper, the related work is reviewed from the aspects of behaviour of P2P lending participants, conflict of interest among $\mathrm{P} 2 \mathrm{P}$ lending participants, and evolutionary game theory.

First, the behaviour of P2P lending participants is the main focus of this work. In previous studies, Berkovich proved that there is a herding behaviour in P2P lending [26]. Herzenstein et al. found that there is an obvious herding effect in the P2P loans closing to full bids, while the herding effect is weakened in loans that have full bids [27]. Liu et al. pointed out that friends with close offline relationships would have a stronger herding effect than friends with ordinary offline relationships in P2P lending [13]. Jiang et al. found that the automatic bidding mechanism can weaken the herding effect and present reasonable herding behaviour in P2P lending [28]. Kim pointed out that the rationality of investors' herding behaviour in P2P lending is not deterministic but changes with the investors' credit evaluation methods in each market [29]. Yang et al. pointed out that better operational capabilities, profitability, and platform security can help to improve investors' investment behaviour [30]. Ding et al. proved that a good reputation can reduce the defaulting probability of borrowers and effectively restrain their defaulting behaviour of borrowers [16]. Ge et al. pointed out that social media behaviours of borrowers, especially self-disclosure behaviours, have an important impact on the defaulting probability of borrowers on P2P lending websites [17]. Du et al. found that text message reminders, which convey lenders' positive expectations, considerably increase the possibility of borrower's repayment [31]. Yu and Shen conducted a study of existing P2P lending regulatory system in China and found that the strict regulations of P2P lending platforms limit their ability to maintain the role of a broker, which in turn jeopardized the commercial sustainability of P2P lending platform [32].
Second, the conflict of interests among the P2P lending participants is another important stream in this paper. The stakeholder is defined broadly as any group or individual that can influence the achievement of an organization's goals or be affected by the achievement thereof [9]. Bachmann analysed the external stakeholders in the P2P lending platform through the method proposed by Freeman [5]. Wei and Lin divided the main stakeholders involved in P2P lending market into borrowers, lenders, and P2P lending platforms and developed a game model based on the general characteristics of the market and stakeholders' incentives [19]. Cohen and Sundararajan divided the stakeholders of P2P sharing economic platform into governmental and nongovernmental stakeholders and noted that the regulatory issues on $\mathrm{P} 2 \mathrm{P}$ sharing economic platform can be resolved through self-regulation [33]. In this paper, we divided the P2P lending stakeholders into regulatory authorities, P2P lending platforms, borrowers, and investors. There are obvious conflicts of interest among them. For instance, Chen and Tsai pointed out that noncompliant operations and fraudulent behaviour of P2P lending platforms would force investors to encounter the defaulting risk and loss of interests [10]. Zhang and Wang found that the high regulatory costs and rent-seeking behaviours of regulatory authorities posed the operational risk to the P2P lending platforms and damage the interests of platforms [12].

Third, the third stream of the literature review is the introduction of EGM and its applications. Evolutionary game theory was proposed in the 1970s, which emphasized on the importance of replicator dynamics when players with bounded rationality would adjust their strategies in line with their previous actions, especially through successful strategies $[34,35]$. In recent years, evolutionary game theory is widely used in the field of economics and finance. For instance, Antoci et al. constructed an EGM between visitors and firms with replicator dynamics and found that such a dynamic process may lead to welfare-improving attractive Nash equilibrium [36]. Zhao et al. adopted an EGM to explore the cooperation or competition between Chinese e-commerce financial institutions and commercial banks [37]. Zhang et al. analysed the investment decision process in cyber offender-defender interaction by an EGM [38]. Li et al. used the two-player EGM to simulate the performance of supply chain members under the environment of financial risk [39]. Yang and Fu constructed an EGM to analyse the equilibrium strategies of inclusive financial institutions and the poor in poverty-reduction activities [40]. Liu and Xia constructed an EGM between borrowers and lenders in P2P lending market to study the impact of evolutionary equilibrium strategies of lenders and borrowers' behavioural strategies on the risk to the P2P lending platforms under bounded rationality [20].

To sum up, although the aforementioned literature has discussed either the behaviour of the P2P lending participant or the EGM, there are still limitations that need to be addressed. The following conclusions can be summarized. 
(1) An empirical approach [26-30] or a qualitative approach [31, 32] to investigate the behaviour of a single participant in the $\mathrm{P} 2 \mathrm{P}$ lending is popular in the existing literature. However, a quantitative approach to study the interaction among multiple P2P lending participants regarding sustainable operations is ignored. In this paper, we studied the interaction and interest-cooperation mechanisms among the P2P lending participants to achieve sustainability of P2P lending.

(2) There are conflicts of interest among the major P2P lending participants $[10,12]$. Thus, it is necessary to understand the interest and interactions of P2P lending participants to coordinate the interest among them for achieving sustainable development of the P2P lending industry.

(3) According to the aforementioned literature, the EGM of two game groups or two players is often applied in studies [20, 36-40]. However, practical cases usually involve more than two participants. In this context, we formulate an EGM of three players including regulatory authorities, P2P lending platforms, and borrowers for the sustainability of P2P lending.

\section{Model Formulation}

3.1. Problem Description. P2P lending participants include regulatory authorities, P2P lending platforms, borrowers, and investors, as shown in Figure 1. The behaviour of investors is significantly affected by both P2P lending platforms and borrowers [41, 42]. In detail, a good reputation can attract more investors to invest in P2P lending [43]. Moreover, the lack of regulation, noncompliant operation of $\mathrm{P} 2 \mathrm{P}$ lending platforms, and defaulting behaviour of borrowers are the main causes of chaos in P2P lending industry. Thus, regulatory authorities, P2P lending platforms, and borrowers are considered to be the three most influential stakeholders for the sustainability of P2P lending industry. The research on the sustainability of the P2P lending can also simplify the discussion of behavioural strategy chosen by regulatory authorities, $\mathrm{P} 2 \mathrm{P}$ lending platforms, and borrowers in their conflict of interests.

More specifically, regulatory authorities are the makers of rules and policies in the $\mathrm{P} 2 \mathrm{P}$ lending industry and play an important role in regulating the normal operation of the $\mathrm{P} 2 \mathrm{P}$ lending market and ensuring the safety of funds of all participants. Meanwhile, regulatory authorities, as the participants in $\mathrm{P} 2 \mathrm{P}$ lending market, have their own goals and interests and influence the expectations and actions of other participants. P2P lending platforms are the operational entity for the P2P lending market and the medium of P2P lending users. $\mathrm{P} 2 \mathrm{P}$ lending platforms need to follow the competition rules of the market, regulate their own behaviour according to the policies and regulations of the Internet finance, and ensure the security of P2P lending transactions. The borrowers are companies or individuals who apply for a loan to an idle fund investor through a P2P lending platform. These aforementioned three participants often have conflict of interest when pursuing their maximum interests respectively. The conflict of interest among the three participants will affect the order of the P2P lending market.

In addition, with the existence of information asymmetry [20], it is difficult for regulatory authorities to use fragmented or even erroneous information to determine whether a $\mathrm{P} 2 \mathrm{P}$ lending platform is operating in compliance. Furthermore, the platforms fail to know if the borrowers adopt a "repayment" strategy due to the incomplete borrowing information. Similarly, borrowers also do not know any information about other participants. Thus, a dynamic game exists in the interaction among regulatory authorities, platforms, and borrowers. In other words, since the three participants are bounded rationality, the behavioural decision is closely related to their previous behaviours. Therefore, developing an EGM on how to balance the interests among the three participants with incomplete information is the main focus of the work described as follows.

\subsection{Assumptions and Parameter Setting}

Assumption 1. The EGM has only three participants, where the regulatory authorities conduct supervision and inspection of the operation of the P2P lending platforms and formulate corresponding regulatory policies; P2P lending platforms are responsible for the release of loan information and reviewing borrowers' information and the borrowers' loan through the P2P lending platforms.

Assumption 2. The three $\mathrm{P} 2 \mathrm{P}$ lending participants aim to achieve a self-benefit maximization. As the regulator in the financial market, the regulatory authorities achieve the goal of maximizing the benefits of regulation. P2P lending platforms, as financial intermediaries, aim to pursue maximum profit. Borrowers pursue their own maximum income.

Assumption 3. The three participants of P2P lending are bounded to rationality. We abandon the classical game theory and choose the evolutionary game theory as the main research method, because the bounded rationality of the $\mathrm{P} 2 \mathrm{P}$ lending participants is more aligned with the actual situation.

Assumption 4. The set of strategies of the regulatory authorities is $G=$ \{strict supervision, general supervision $\}$. The set of strategies of $\mathrm{P} 2 \mathrm{P}$ lending platforms is $P=\{$ compliant operation, noncompliant operation $\}$. The set of strategies of $\mathrm{P} 2 \mathrm{P}$ lending borrowers is $B=$ \{repayment, default $\}$. The game among the three participants is based on incomplete information: $x$ represents the possibility of regulatory authorities choosing "strict supervision" strategy; then, $1-x$ represents the possibility of regulatory authorities choosing "general supervision" strategy, and $0 \leq x \leq 1 . y$ represents the possibility of P2P lending platforms choosing "compliant operation" strategy; then, $1-y$ represents the possibility of 


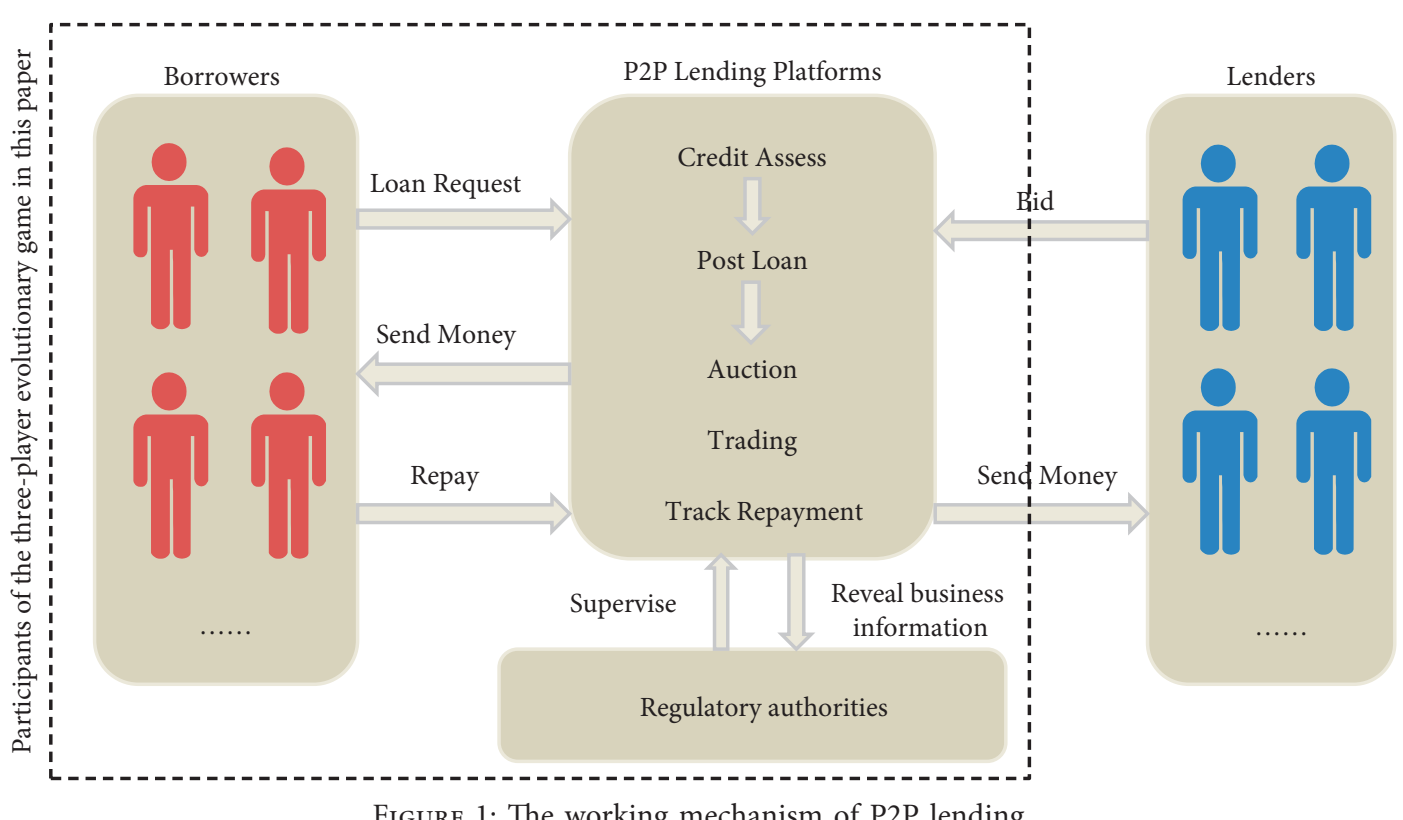

Figure 1: The working mechanism of P2P lending.

P2P lending platforms choosing "noncompliant operation" strategy, and $0 \leq y \leq 1 . z$ represents the possibility of $\mathrm{P} 2 \mathrm{P}$ borrowers choosing "repayment" strategy; then, $1-\mathrm{z}$ represents the possibility of $\mathrm{P} 2 \mathrm{P}$ borrowers choosing "default" strategy, and $0 \leq z \leq 1$.

According to the aforementioned assumptions, the main factors that are considered by the regulatory authorities, P2P lending platforms, and borrowers in the behavioural strategies, are clarified, and the parameters involved in the model are defined, as shown in Table 1.

\subsection{Return Matrix of a Three-Player Evolutionary Game Model}

Case 1 strict supervision, compliant operation, repayment\}. The regulatory cost of regulatory authorities is $C_{1}$, and the reward of regulatory authorities for compliant P2P lending platforms is $w R$. Therefore, the revenue of regulatory authorities of strict supervision is $-C_{1}-w R$. The normal revenue of the $\mathrm{P} 2 \mathrm{P}$ lending platforms is $R$, and the reward obtained by a compliant $\mathrm{P} 2 \mathrm{P}$ lending platforms is $\mathrm{wR}$, so the revenue of platforms is $(1+w) R$. The incentive for repayment of $\mathrm{P} 2 \mathrm{P}$ borrowers is $V$, and the sum of principal and interest required is $H$. Therefore, the revenue of the borrowers who choose repayment is $V-H$.

Case 2 strict supervision, noncompliant operation, repayment\}. The normal revenue of $\mathrm{P} 2 \mathrm{P}$ lending platforms is $R$, and the extra revenue gained by $\mathrm{P} 2 \mathrm{P}$ lending platforms through noncompliant operation is $\Delta R$. The punishment coefficient of the regulatory authorities for noncompliant $\mathrm{P} 2 \mathrm{P}$ lending platforms is $\theta$, so the return of platforms is $(1-\theta)(R+\Delta R)$. Meanwhile, the regulatory cost of regulatory authorities is $C_{1}$. Therefore, the revenue of regulatory authorities of strict supervision is $-C_{1}+\theta(R+\Delta R)$. The sum of principal and interest required is $H$. Therefore, the revenue of the borrowers who choose repayment is $-H$.

Case 3 \{general supervision, compliant operation, repayment\}. The regulatory cost of regulatory authorities is $C_{2}$, and the damage caused by general supervision of regulatory authorities is $E$. Therefore, the revenue of regulatory authorities of general supervision is $-C_{1}-E$. The revenue of $\mathrm{P} 2 \mathrm{P}$ lending platforms is $R$. The incentive for repayment of P2P borrowers is $V$, and the sum of principal and interest required is $H$. Therefore, the revenue of the borrowers who choose repayment is $V-H$.

Case 4 \{general supervision, noncompliant operation, repayment\}. The regulatory cost of regulatory authorities is $C_{2}$, and the damage caused by regulatory authorities general supervision is $E$. Therefore, the revenue of regulatory authorities of general supervision is $-C_{1}-E$. The normal revenue of $\mathrm{P} 2 \mathrm{P}$ lending platforms is $R$, and the extra revenue gained by $\mathrm{P} 2 \mathrm{P}$ lending platforms through noncompliant operation is $\Delta \mathrm{R}$, so the revenue of $\mathrm{P} 2 \mathrm{P}$ lending platforms is $R+\Delta R$. The sum of principal and interest required is $H$. Therefore, the revenue of the borrowers who choose repayment is $-H$.

Case 5 \{strict supervision, compliant operation, default\}. The regulatory cost of regulatory authorities is $C_{1}$. The reward of regulatory authorities for compliant P2P lending platforms is $w R$. Therefore, the revenue of regulatory authorities of strict supervision is $-C_{1}-w R$. The normal revenue of $\mathrm{P} 2 \mathrm{P}$ lending platforms is $R$, and the reward obtained by compliant $\mathrm{P} 2 \mathrm{P}$ lending platforms is $\mathrm{wR}$. The loss coefficient of P2P lending platforms due to P2P borrowers default is $f$, so the revenue of $\mathrm{P} 2 \mathrm{P}$ lending platforms is $(1+w)$ $(1-f) R$. The sum of the principal and interest required is $H$, and the defaulting opportunity cost of P2P borrowers is $D$. 
TABLE 1: Symbols and descriptions of the parameters.

\begin{tabular}{|c|c|c|}
\hline Items & Parameter & Description \\
\hline $\begin{array}{l}\text { Regulatory } \\
\text { authorities }\end{array}$ & $\begin{array}{l}x \\
C_{1} \\
C_{2} \\
E\end{array}$ & $\begin{array}{l}\text { The possibility of regulatory authorities choosing "strict supervision" strategy, and } 0 \leq x \leq 1 \\
\text { The costs incurred by regulatory authorities for strict supervision of P2P lending platforms } \\
\text { The costs incurred by regulatory authorities for general supervision of } \mathrm{P} 2 \mathrm{P} \text { lending platforms, and } C_{2}<C_{1} \\
\text { The damage caused by regulatory authorities general supervision of P2P lending platforms }\end{array}$ \\
\hline ns & $\begin{array}{c}y \\
R \\
\Delta R \\
w\end{array}$ & $\begin{array}{l}\text { The possibility of P2P lending platforms choosing "compliant operation" strategy, and } 0 \leq y \leq 1 \\
\text { Normal returns obtained from operation of P2P lending platform } \\
\text { The extra revenue gained by P2P lending platforms through noncompliant operation } \\
\text { The reward coefficient of regulatory authorities for the compliant P2P lending platforms in the case of } \\
\text { strict supervision, and } 0<w<1\end{array}$ \\
\hline & $\theta$ & $\begin{array}{l}\text { The punishment coefficient of regulatory authorities for the noncompliant P2P lending platforms in the } \\
\text { case of strict supervision, and } 0<\theta<1 \\
\text { The loss coefficient of operational income of P2P lending platforms due to P2P borrowers default, and } \\
\qquad 0<f<1\end{array}$ \\
\hline Borrowers & $\begin{array}{l}z \\
H \\
V \\
D\end{array}$ & $\begin{array}{l}\text { The possibility of P2P borrowers choosing "repayment" strategy, and } 0 \leq z \leq 1 \\
\text { The sum of principal and interest that P2P borrowers need to repay in the case of the loan } \\
\text { The positive incentives of } \mathrm{P} 2 \mathrm{P} \text { lending platforms for P2P borrowers' repayment in case P2P lending } \\
\text { platforms operate in compliance } \\
\text { The defaulting opportunity cost of P2P borrowers }\end{array}$ \\
\hline
\end{tabular}

Therefore, the revenue of the borrowers who choose default is $H-D$.

Case 6 strict supervision, noncompliant operation, default $\}$. The normal revenue of $\mathrm{P} 2 \mathrm{P}$ lending platforms is $R$, the extra revenue gained by $\mathrm{P} 2 \mathrm{P}$ lending platforms through noncompliance operation is $\Delta \mathrm{R}$, the punishment coefficient of regulatory authorities for noncompliant $\mathrm{P} 2 \mathrm{P}$ lending platforms is $\theta$, and the loss coefficient of $\mathrm{P} 2 \mathrm{P}$ lending platforms due to $\mathrm{P} 2 \mathrm{P}$ borrowers default is $f$, so the revenue of platforms is $(1-\theta)(1-f)(R+\Delta R)$. At same time, the regulatory cost of regulatory authorities is $C_{1}$. Therefore, the revenue of regulatory authorities of strict supervision is $-C_{1}+\theta(R+\Delta R)$. The sum of principal and interest required is $H$, and the defaulting opportunity cost of $\mathrm{P} 2 \mathrm{P}$ borrowers is $D$. Therefore, the revenue of the borrowers who choose default is $H-D$.

Case 7 \{general supervision, compliant operation, default\}. The regulatory cost of regulatory authorities is $C_{2}$, and the damage caused by regulatory authorities general supervision is $E$. Therefore, the benefit of regulatory authorities' strict supervision is $-C_{1}-E$. The normal revenue of $\mathrm{P} 2 \mathrm{P}$ lending platforms is $R$, and the loss coefficient of $\mathrm{P} 2 \mathrm{P}$ lending platforms due to the default of $\mathrm{P} 2 \mathrm{P}$ borrowers is $f$, so the revenue of $\mathrm{P} 2 \mathrm{P}$ lending platforms is $(1-f) R$. The sum of principal and interest required is $H$, and the defaulting opportunity cost of $\mathrm{P} 2 \mathrm{P}$ borrowers is $D$. Therefore, the revenue of the borrowers who choose default is $H-D$.
Case 8 \{general supervision, noncompliant operation, default\}. The regulatory cost of regulatory authorities is $C_{2}$, and the damage caused by regulatory authorities of general supervision is $E$. Therefore, the revenue of regulatory authorities of strict supervision is $-C_{1}-E$. The normal revenue of $\mathrm{P} 2 \mathrm{P}$ lending platforms is $R$, the extra revenue gained by $\mathrm{P} 2 \mathrm{P}$ lending platforms through noncompliance operation is $\Delta R$, and the loss coefficient of $\mathrm{P} 2 \mathrm{P}$ lending platforms due to $\mathrm{P} 2 \mathrm{P}$ borrowers' default is $f$, so the revenue of platforms is $(1-f)(R+\Delta R)$. The sum of principal and interest required is $H$, and the defaulting opportunity cost of P2P borrowers is $D$. Therefore, the revenue of the borrowers who choose default is $H-D$.

As shown in Figure 2, the return matrix of the EGM among regulatory authorities, P2P lending platforms, and borrowers can be obtained according to the aforementioned statements. It is shown in Table 2.

\section{Model Analysis}

\subsection{Regulatory Authorities}

4.1.1. Replicator Dynamic Equation and Evolutionary Stability Analysis. Assume that the expected returns of regulatory authorities adopting "strict supervision" strategy are $\pi_{G 1}$, the expected returns of regulatory authorities adopting "general supervision" strategy are $\pi_{G 2}$, and the average expected returns of regulatory authorities under the mixed strategies are $\pi_{G}$. Then,

$$
\begin{aligned}
& \pi_{G 1}=y z A_{1}+(1-y) z A_{2}+y(1-z) A_{5}+(1-y)(1-z) A_{6}=-w y R-C_{1}+(1-y) \theta(R+\Delta R), \\
& \pi_{G 2}=y z A_{3}+(1-y) z A_{4}+y(1-z) A_{7}+(1-y)(1-z) A_{8}=-\left(C_{2}+E\right), \\
& \pi_{G}=x \pi_{G 1}+(1-x) \pi_{G 2}=-x y w R-x C_{1}+x(1-y) \theta(R+\Delta R)-(1-x)\left(C_{2}+E\right) .
\end{aligned}
$$




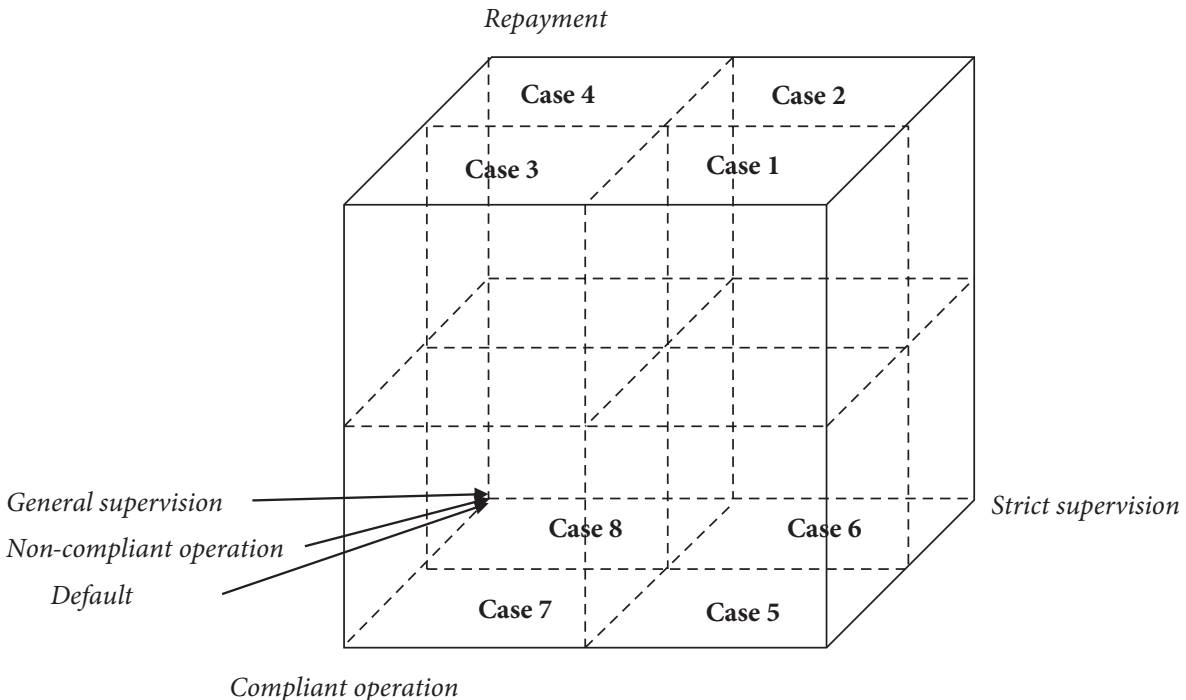

FIgURE 2: The EGM among regulatory authorities, P2P lending platforms, and borrowers.

TABLE 2: Return matrix of the three players: regulatory authorities, P2P lending platforms, and borrowers.

\begin{tabular}{|c|c|c|c|c|}
\hline \multirow{2}{*}{$\begin{array}{c}\text { Regulatory authorities } \\
\text { P2P lending } \\
\text { platforms } \\
\end{array}$} & \multicolumn{2}{|c|}{ Strict supervision $(x)$} & \multicolumn{2}{|c|}{ General supervision $(1-x)$} \\
\hline & $\begin{array}{c}\text { Compliant } \\
\text { operation }(y)\end{array}$ & $\begin{array}{c}\text { Noncompliant } \\
\text { operation }(1-y)\end{array}$ & $\begin{array}{c}\text { Compliant } \\
\text { operation }(y)\end{array}$ & $\begin{array}{l}\text { Noncompliant operation } \\
(1-y)\end{array}$ \\
\hline Borrowers & {$\left[\begin{array}{c}-C_{1}-w R \\
(1+w) R \\
V-H\end{array}\right]$} & {$\left[\begin{array}{c}-C_{1}+\theta(R+\Delta R) \\
(1-\theta)(R+\Delta R) \\
-H\end{array}\right]$} & {$\left[\begin{array}{c}-C_{2}-E \\
R \\
V-H\end{array}\right]$} & {$\left[\begin{array}{c}-C_{2}-E \\
R+\Delta R \\
-H\end{array}\right]$} \\
\hline Default $(1-z)$ & {$\left[\begin{array}{c}-C_{1}-w R \\
(1+w)(1-f) R \\
H-D\end{array}\right]$} & {$\left[\begin{array}{c}-C_{1}+\theta(R+\Delta R) \\
(1-\theta)(1-f)(R+\Delta R) \\
H-D\end{array}\right]$} & {$\left[\begin{array}{c}-C_{2}-E \\
(1-f) R \\
H-D\end{array}\right]$} & {$\left[\begin{array}{c}-C_{2}-E \\
(1-f)(R+\Delta R) \\
H-D\end{array}\right]$} \\
\hline
\end{tabular}

According to EGM, the replicator dynamics system emphasizes the adjustment of the respective probabilities of choosing two strategies based on the previous results of games. It is denoted by the differential equation and can be used to describe the frequency or the frequency of such strategies in a population [44].

$$
\begin{aligned}
F(x)= & \frac{\mathrm{d} x}{\mathrm{~d} t}=x\left(\pi_{G 1}-\pi_{G}\right)=x(1-x)\left[-y w R-C_{1}\right. \\
& \left.+(1-y) \theta(R+\Delta R)+\left(C_{2}+E\right)\right] .
\end{aligned}
$$

For convenience of calculation, make $y_{0}=((\theta(R+\Delta R)$ $\left.\left.+C_{2}+E-C_{1}\right) /(w R+\theta(R+\Delta R))\right)$.

(1) When $y=y_{0}$, then $F(x) \equiv 0$; this shows that all levels are stable

(2) When $y \neq y_{0}$, make $F(x)=0$; then, $x=0, x=1$ are two stable points

Let $F^{\prime}(x)$ be the derivative of $x$ and derived from $F(x)$ :

$$
\begin{aligned}
F^{\prime}(x)= & \frac{\mathrm{d} F(x)}{\mathrm{d} x}=(1-2 x)\left[-y w R-C_{1}+(1-y) \theta(R+\Delta R)\right. \\
& \left.+\left(C_{2}+E\right)\right] .
\end{aligned}
$$

According to the requirements of the evolutionary stability strategy (ESS), $F^{\prime} \quad(x)<0$. Therefore, $\theta$ $(R+\Delta R)+C_{2}+E-C_{1}$ are analysed, because $0<x<1$, $0<y<1$, and $0<z<1$, and ESSs are obtained considering the following two scenarios.

Scenario 1. When $\theta(R+\Delta R)+C_{2}+E-C_{1}<0, \quad-y w R-$ $C_{1}+(1-y) \quad \theta \quad(R+\Delta R)+\left(C_{2}+E\right)<0 . \quad$ Therefore, when $x=0, F^{\prime}(x)<0$; when $x=1, F^{\prime}(x)>0$; therefore, $x=0$ is an ESS.

Scenario 2. When $\theta(R+\Delta R)+C_{2}+E-C_{1}>0$, scilicet, $\theta$ $(R+\Delta R)+C_{2}+E>C_{1}$. If $y>y_{0}$, then, when $x=0, F^{\prime}(x)<0$; when $x=1, F^{\prime}(x)>0$. So, $x=0$ is an ESS. If $y<y_{0}$, then, when $x=0, F^{\prime}(x)>0$; when $x=1, F^{\prime}(x)<0$. Therefore, $x=1$ is an ESS.

According to the analysis, the dynamic evolutionary trend of regulatory authorities is shown in Figure 3, and thereby, Propositions 1 and 2 are obtained.

Proposition 1. When the initial state of the behavioural strategy of the regulatory authorities is in space $V_{1}$, that is, $\theta$ $(R+\Delta R)+C_{2}+E-C_{1}<0, x=0$ is the equilibrium point, and the regulatory authorities will adopt the strategy of "general supervision." Therefore, when the cost of strict supervision by 


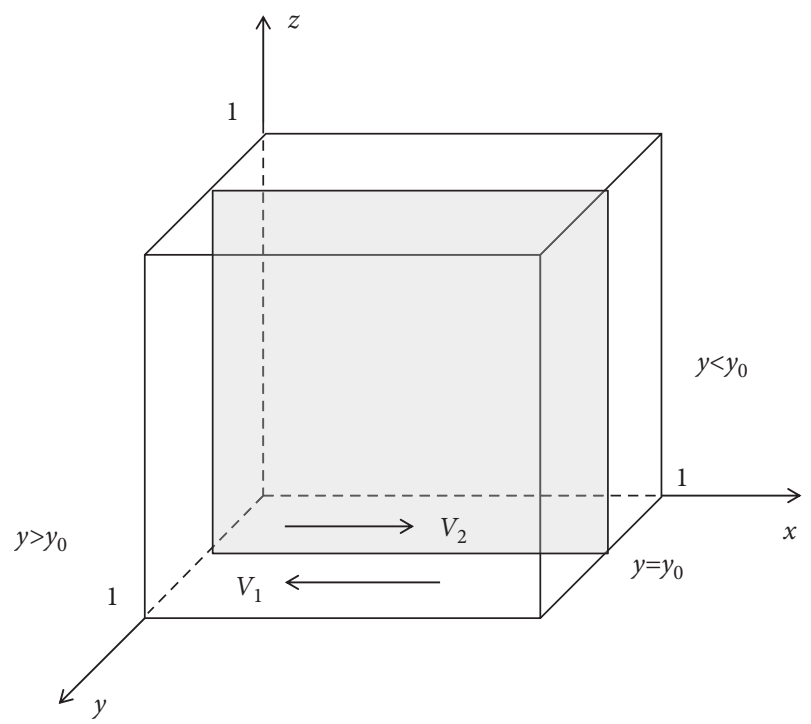

Figure 3: The dynamic trend diagram of regulatory authorities.

the regulatory authorities exceeds the benefits obtained, the regulatory authorities will adopt the strategy of "general supervision."

Proposition 2. When the initial state of the behavioural strategy of regulatory authorities is in space $V_{2}$, that is, $\theta$ $(R+\Delta R)+C_{2}+E-C_{1}>0, x=1$ is the equilibrium point, and the regulatory authorities will adopt the strategy of "strict supervision." Therefore, when the cost of strict supervision by the regulatory authorities is less than the benefits obtained, the regulatory authorities will adopt the strategy of "strict supervision."

4.1.2. Parameter Analysis. As shown in Figure 3, when other parameters are fixed, $w$ is increased, and $y_{0}$ becomes smaller. When $y_{0}$ becomes smaller, space of $V_{1}$ becomes larger. That is to say, when the incentive of the regulatory authorities for the compliant P2P lending platforms increases, the regulatory authorities tend to select the strategy of "general regulation." Additionally, this shows that when the rewards of regulatory authorities for the compliant P2P lending platforms increase, $\mathrm{P} 2 \mathrm{P}$ lending platforms will select the strategy of "compliant operation," so the regulatory authorities adopt the strategy of "general supervision" at this point. Similarly, when $C_{1}$ increases, space of $V_{1}$ becomes larger; in other words, when the cost of strict supervision by regulatory authorities increase, the pressure of high regulatory costs will be imposed on the regulatory authorities, which would prompt them to adopt the strategy of "general supervision."

4.1.3. Evolutionary Analysis of Regulatory Authorities. The two aforementioned scenarios are aligned with the current regulatory situation of $\mathrm{P} 2 \mathrm{P}$ lending industry in China. Due to the high cost of strict supervision, the regulatory authorities adopted the "general supervision" strategy in the early stage of the P2P lending industry, which directly prompted chaos therein. When the P2P lending industry is in trouble, the regulatory authorities raises the threshold to the entry of the P2P lending industry, which damages the openness and sustainability of the P2P lending industry. In addition, this explains the reasons why the P2P lending industry is in trouble from the perspective of regulation in China. In order to overcome this dilemma, the following measures can be taken. On the one hand, the central regulatory authority should formulate development policies and regulatory system to provide guidance for the local regulatory authorities. On the other hand, local regulatory authorities should be responsible for the standard guidance, filing management, risk prevention, and disposal concerning the P2P lending platforms, by adopting modern financial technology to optimize the regulatory approach of the P2P lending platforms, improve regulatory efficiency, reduce regulatory costs, and achieve a balance between efficiency and economy in regulation of the P2P lending industry.

\subsection{P2P Lending Platforms}

4.2.1. Replicator Dynamic Equation and Evolutionary Stability Analysis. Assume that the expected returns of the P2P lending platforms adopting "compliant operation" strategy are $\pi_{P 1}$, the expected returns of the P2P lending platforms adopting "noncompliant operation" strategy will be $\pi_{P 2}$, and the average expected returns of $\mathrm{P} 2 \mathrm{P}$ lending platforms under the mixed strategies will be $\pi_{P}$. Then,

$$
\begin{aligned}
& \pi_{P 1}=x z B_{1}+(1-x) z B_{3}+x(1-z) B_{5}+(1-x)(1-z) B_{7}=(x w+1)(1-f+z f) R, \\
& \pi_{P 2}=x z B_{2}+(1-x) z B_{4}+x(1-z) B_{6}+(1-x)(1-z) B_{8}=(R+\Delta R)(1-x \theta)(1-f+z f), \\
& \pi_{P}=y \pi_{P 1}+(1-y) \pi_{P 2}=(1-f+z f)[y R(x w+1)+(1-y)(R+\Delta R)(1-x \theta)] .
\end{aligned}
$$

The replicator dynamics equation of $\mathrm{P} 2 \mathrm{P}$ lending platforms is shown in 


$$
\begin{gathered}
F(y)=\frac{\mathrm{d} y}{\mathrm{~d} t}=y\left(\pi_{P 1}-\pi_{P}\right)=y(1-y)(1-f+z f) \\
\cdot[(x w+1) R-(R+\Delta R)(1-x \theta)] .
\end{gathered}
$$

For convenience of calculation, make $x_{0}=(\Delta R /(w R+$ $\theta R+\theta \Delta R))$.

(1) When $x=x_{0}$, then $F(y) \equiv 0$; this shows that all levels are stable

(2) When $x \neq x_{0}$, make $F(y)=0$; then $y=0$ and $y=1$ are two stable points $F(y)$ :

Let $F^{\prime}(y)$ be $F(y)$ the derivative of $y$ and derived from

$$
\begin{aligned}
F^{\prime}(y)= & \frac{\mathrm{d} F(y)}{\mathrm{d} y}=(1-2 y)(1-f+z f)[(x w+1) R \\
& -(R+\Delta R)(1-x \theta)] .
\end{aligned}
$$

According to the requirements of the ESS, $F^{\prime}(y)<0$, and $0<z<1, \quad 0<f<1$, so $1-f+z f>0$. Therefore, $(x w+1)$ $R-(R+\Delta R)(1-x \theta)$ are analysed, and ESSs are obtained considering the following two scenarios.

Scenario 3. When $x_{0}>1$, scilicet, $(1-\theta) \Delta R>(w+\theta) R$, constant $x<x_{0}$. Therefore, when $y=0, F^{\prime}(y)<0$; when $y=1$, $F^{\prime}(y)>0$; therefore, $y=0$ is an ESS.

Scenario 4. When $x_{0}<1$, scilicet, $(1-\theta) \Delta R<(w+\theta) R$. If $x>x_{0}$, then, when $y=1, F^{\prime}(y)<0$; when $y=0, F^{\prime}(y)>0$. So $y=1$ is an ESS. If $x<x_{0}$, then, when $y=1, F^{\prime}(y)>0$; when $x=0, F^{\prime}(y)<0$; therefore, $y=0$ is an ESS.

To clearly describe the results, the dynamic evolution trend of P2P lending platforms is presented in Figure 4, from which Propositions 3 and 4 are obtained.

Proposition 3. When the initial state of the behavioural strategy of the P2P lending platforms is in space $V_{3}$, that is, $(1-\theta) \Delta R>(w+\theta) R, y=0$ is the equilibrium point, the $P 2 P$ lending platforms will adopt the strategy of "noncompliant operation." Therefore, considering rewards and punishments of the local regulatory authorities for P2P lending platforms, when the revenue of the $P 2 P$ lending platforms through compliant operations is less than that obtained through noncompliant operations, and P2P lending platforms will eventually select the strategy of "noncompliant operation."

Proposition 4. When the initial state of the behavioural strategy of the P2P lending platforms is in space $V_{4}$, that is $(1-\theta) \Delta R<(w+\theta) R, y=1$ is the equilibrium point, the $P 2 P$ lending platforms will adopt the strategy of "compliant operation." Therefore, considering rewards and punishments of the local regulatory authorities for the P2P lending platforms, when the revenue of $P 2 P$ lending platforms through compliant operations exceeds what was obtained through noncompliant operations, P2P lending platforms will eventually choose the strategy of "compliant operation."

4.2.2. Parameter Analysis. As shown in Figure 4, the initial state space $V_{3}, V_{4}$ of the operational strategy of the P2P lending platform is related to the size of $x_{0}$. When $w$ is increased, $x_{0}$ turns smaller, and the space of $V_{4}$ turns larger. This indicates that when regulatory authorities increase the incentives of compliant P2P platforms, P2P lending platforms will be more inclined to operate in noncompliance. Similarly, when $\theta$ increases, $x_{0}$ becomes smaller and the space of $V_{4}$ becomes larger. In other words, P2P lending platforms are more inclined to operate in compliance when regulatory authorities increase penalties for noncompliant $\mathrm{P} 2 \mathrm{P}$ lending platforms. When $R$ is larger, $x_{0}$ becomes smaller, and the space of $V_{4}$ becomes larger. This shows that when the revenue of compliant P2P lending platforms increases, $\mathrm{P} 2 \mathrm{P}$ lending platforms will be more inclined to operate in compliance. In addition, When $R$ increases, $x_{0}$ becomes larger, and the space of $V_{3}$ becomes larger, indicating that P2P lending platforms tend to be noncompliant when P2P lending platforms earn more benefits through noncompliant operation.

4.2.3. Evolutionary Results Analysis of $P 2 P$ Lending Platforms. According to the previously mentioned analysis, $\mathrm{P} 2 \mathrm{P}$ lending platforms choose their own strategies for the purpose of maximum profit. Therefore, to enable P2P lending platforms to adopt the strategy of "compliant operation" actively, their operational profit should be increased. By adjusting relevant parameters to make $(1-\theta)$ $\Delta R<(w+\theta) R$, the following measures can be taken. The reward coefficient for compliant $\mathrm{P} 2 \mathrm{P}$ lending platforms should increase. The penalties for noncompliant P2P lending platforms should also increase. The regulatory authorities should build a good business environment for compliant $\mathrm{P} 2 \mathrm{P}$ lending platforms, such as providing preferential policies, increasing publicity about compliant P2P lending platforms, punishing noncompliant P2P lending platforms, and guiding investors to invest in compliant P2P lending platforms.

\subsection{P2P Borrowers}

4.3.1. Replicator Dynamic Equation and Evolutionary Stability Analysis. Assume that the expected returns of P2P borrowers adopting "repayment" strategy are $\pi_{B 1}$, the expected returns of P2P borrowers adopting "default" strategy are $\pi_{B 2}$, and the average expected returns of P2P borrowers under mixed strategies are $\pi_{B}$. Then, 


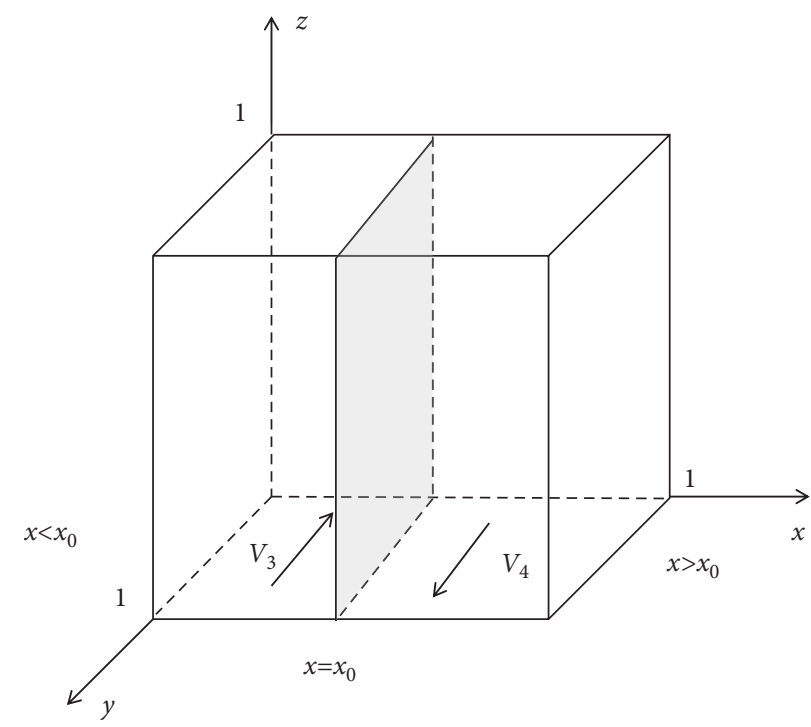

Figure 4: The dynamic trend diagram of P2P lending platforms.

$$
\begin{aligned}
& \pi_{B 1}=x y C_{1}+x(1-y) C_{2}+y(1-x) C_{3}+(1-x)(1-y) C_{4}=y V-H, \\
& \pi_{B 2}=x y C_{5}+x(1-y) C_{6}+y(1-x) C_{7}+(1-x)(1-y) C_{8}=H-D, \\
& \pi_{B}=z \pi_{B 1}+(1-z) \pi_{B 2}=z(y V-H)+(1-z)(H-D) .
\end{aligned}
$$

The replicator dynamics equation of P2P borrowers is shown and presented by

$$
F(z)=\frac{\mathrm{d} y}{\mathrm{~d} t}=y\left(\pi_{P 1}-\pi_{P}\right)=z(1-z)(y V+D-2 H) .
$$

For ease of calculation, make $y_{1}=((2 H-D) / V)$.

(1) When $y=y_{1}$, then $F(z) \equiv 0$; this shows that all levels are stable

(2) When $y \neq y_{1}$, make $F(z)=0$; then, $z=0$ and $z=1$ are two stable points $F(z)$ :

Let $F^{\prime}(z)$ be $F(z)$ the derivative of $z$ and derived from

$$
F^{\prime}(z)=\frac{\mathrm{d} F(z)}{\mathrm{d} z}=(1-2 z)(y V+D-2 H)
$$

According to the requirements of the ESS, $F^{\prime}(z)<0$, and $0<y<1$. Therefore, $y V+D-2 H$ are analysed, and ESSs are obtained considering the following two scenarios.

Scenario 5. When $y_{1}>1$, scilicet, $V+D<2 H$, constant $y<y_{1}$. Therefore, when $z=0, F^{\prime}(z)<0$; when $z=1, F^{\prime}(z)>0$; therefore, $z=0$ is an ESS.

Scenario 6. When $y_{1}<1$, scilicet, $V+D>2 H$. If $y>y_{1}$, then, when $z=0, F^{\prime}(z)>0$; when $z=1, F^{\prime}(z)<0$. So, $z=1$ is an ESS. If $y<y_{1}$, then, when $z=0, F^{\prime}(z)<0$; when $z=1, F^{\prime}(z)>0$. Therefore, $z=0$ is an ESS.
To explicitly analyse the results, the dynamic evolution trend of the P2P borrowers is depicted in Figure 5. Besides, from Figure 5, Propositions 5 and 6 are obtained.

Proposition 5. When the initial state of the behavioural strategy of $\mathrm{P} 2 \mathrm{P}$ borrowers is in space $V_{5}$, that is $\mathrm{V}+\mathrm{D}<2 \mathrm{H}$, $z=0$ is the equilibrium point, $P 2 P$ borrowers will adopt the strategy of "default." Therefore, considering the positive incentives of compliant $P 2 P$ lending platforms for borrowers' repayment and the defaulting opportunity cost of borrowers, when the revenue of $P 2 P$ borrowers through default exceeds that obtained through repayment, P2P borrowers will eventually choose the strategy of "default."

Proposition 6. When the initial state of the behavioural strategy of $P 2 P$ borrowers is in space $V_{6}$, that is $V+D>2 H$, $z=1$ is the equilibrium point, the P2P borrowers will adopt the strategy of "repayment." Therefore, considering the positive incentives of compliant $P 2 P$ lending platforms for P2P borrowers' repayment and the defaulting opportunity cost of borrowers, when the revenue of $P 2 P$ borrowers through repayment exceeds that obtained through default, $P 2 P$ borrowers will eventually choose the strategy of "repayment."

4.3.2. Parameter Analysis. As shown in Figure 5, the initial state space $V_{5}, V_{6}$ of repayment strategy of P2P borrowers is related to the size of $y_{1}$. When $V$ increases, $y_{1}$ becomes smaller, and space $V_{6}$ will become larger. This indicates that $\mathrm{P} 2 \mathrm{P}$ borrowers are more inclined to repay when positive incentive of compliant $\mathrm{P} 2 \mathrm{P}$ lending platforms for $\mathrm{P} 2 \mathrm{P}$ borrowers' repayment increases. Similarly, when $D$ 


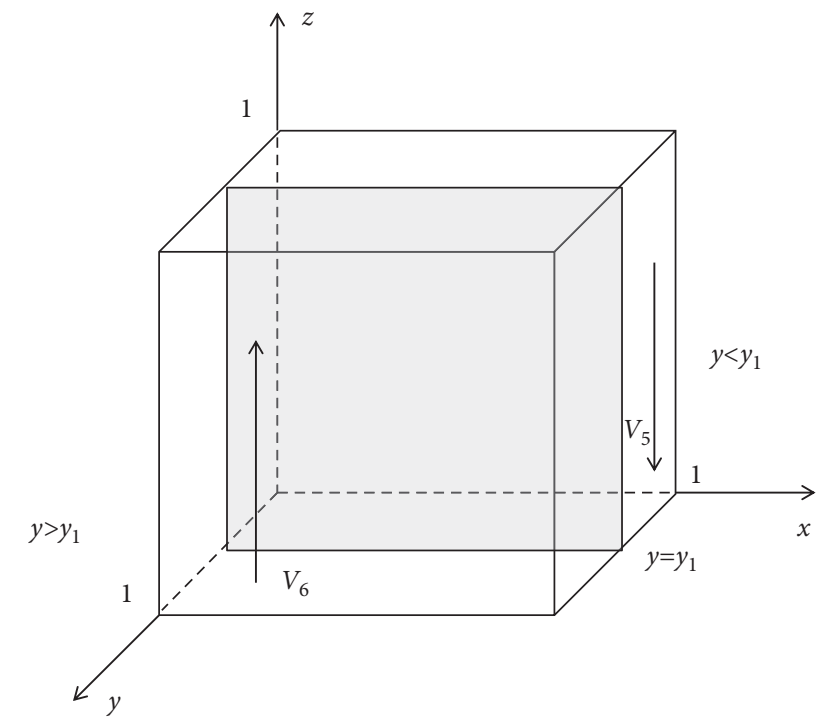

Figure 5: The dynamic trend diagram of P2P lending borrowers.

increases, $y_{1}$ becomes smaller, and space $V_{6}$ becomes larger. That is, when the defaulting opportunity costs of borrowers increases, P2P borrowers will be more willing to choose repayment. In addition, when $H$ increases, $y_{1}$ becomes larger, and space $V_{5}$ becomes larger. That is, the more the principal and interest $\mathrm{P} 2 \mathrm{P}$ borrowers need to repay, the more the $\mathrm{P} 2 \mathrm{P}$ borrowers tend to default.

4.3.3. Evolutionary Results Analysis of P2P Borrowers. When P2P lending platforms lack the necessary repayment incentive and the defaulting opportunity costs of borrowers are low, the borrower is more willing to choose the "default" strategy. Therefore, given the nature of the "economic man" among P2P borrowers, for P2P borrowers to choose the "repayment" strategy, the benefits of their repayments and the defaulting cost should increase. By adjusting the corresponding parameters to make $V+D>2 H$, P2P lending platforms can take relevant measures. First, the loan amount of the repaying borrowers should be increased. The credit rating and positive incentive of repaying borrowers should also increase. Second, the information disclosure system should be improved. Borrowers who default by escaping debts should be announced to the public in a timely manner, and their names added to the list of untrustworthy persons. The defaulting opportunity cost of borrowers should increase to restrain the behaviour of borrowers.

4.4. Comprehensive Analysis of the Three P2P Lending Participants. The aforementioned three P2P lending participants should be regarded as a system for comprehensive analysis, and the impact of P2P lending participants' behavioural strategies on the sustainability of $\mathrm{P} 2 \mathrm{P}$ lending is also explored. Figures 3-5 show that the dynamic evolutionary trend of regulatory authorities, P2P lending platforms, and borrowers are divided into two spatial sets, respectively. The initial state of each participant is arranged and combined to obtain the equilibrium points of the three players in each space, as shown in Table 3.
TABle 3: The behavioural strategies of three P2P lending participants in each space.

\begin{tabular}{lcccc}
\hline Space & \multicolumn{2}{c}{$V_{1}$} & \multicolumn{2}{c}{$V_{2}$} \\
& $V_{3}$ & $V_{4}$ & $V_{3}$ & $V_{4}$ \\
\hline$V_{5}$ & $(0,0,1)$ & $(0,1,0)$ & $(1,0,0)$ & $(0,0,1)$ \\
$V_{6}$ & $(0,0,1)$ & $(0,1,1)$ & $(1,0,1)$ & $(0,0,1)$ \\
\hline
\end{tabular}

When the initial state of three $\mathrm{P} 2 \mathrm{P}$ lending participants is located in the intersection of space $V_{2}, V_{3}$, and $V_{4}$, the behavioural strategies of the participants will converge to $(1,0,0)$. That is, in the early stage of P2P lending industry development, since there are short-sightedness and selfinterest, most of $\mathrm{P} 2 \mathrm{P}$ lending platforms engaged in noncompliant operation to gain the extra revenue. Without the necessary incentives and penalties, even if the regulatory authorities adopt strict regulatory measures, P2P lending platforms will eventually adopt the strategy of "noncompliant operation." Therefore, in this case, the regulatory authorities should formulate corresponding punishment and incentive policies for $\mathrm{P} 2 \mathrm{P}$ lending platforms to achieve sustainability of P2P lending. So, the proportion of P2P lending platforms engaged in compliant operation will be greatly increased. Meanwhile, P2P borrowers will also choose the strategy of "default" due to the lack of necessary incentives. P2P lending platforms should also give repayment incentives to improve the rate of repayment.

When $x=1, y=1, z=1$, that is, the regulatory authorities choose strict supervision, P2P lending platforms choose compliant operation, and borrowers choose repayment, which is also the regulatory goal of $\mathrm{P} 2 \mathrm{P}$ lending industry in China. In the early stage of P2P lending industry development, strict supervision by regulatory authorities is indispensable. As can be seen from Figures 3 and 4, this evolution equilibrium state occurs when $y_{0}$ is large and $x_{0}$ is small. That is, when $\mathrm{P} 2 \mathrm{P}$ lending industry is in early stage, only regulatory authorities can ensure P2P lending platforms to operate in compliance by carrying out strict supervision, and $\mathrm{P} 2 \mathrm{P}$ lending platforms can ensure borrowers to repayment by adopting incentive measures. In this way, the sustainability of P2P lending industry can be achieved.

When the initial state of $\mathrm{P} 2 \mathrm{P}$ lending participants is in the intersection of spaces $V_{1}, V_{4}$, and $V_{6}$, the behavioural strategies of the participants will converge to $(0,1,1)$. That is, from a long-term perspective, when the initial group proportion of $\mathrm{P} 2 \mathrm{P}$ lending platforms engaged in compliant operations and the borrowers adopting repayment strategy is sufficiently high, P2P lending industry has already formed a certain degree of self-discipline. Even without strict supervision by regulatory authority, P2P lending platforms and borrowers will also take the "compliant operation" and "repayment" strategies, which is the goal of achieving sustainable development of P2P lending industry.

\section{Numerical Analysis}

To further validate the proposed model, computational studies are used to analyse the impact of changes in parameters on the evolutionary results. This paper refers to the 
transaction data of China's P2P lending platform in 2019 to set the interval range of each parameter. By the end of 2019, there were 343 good-performance platforms and 6156 problem platforms in China (see https://m.wdzj.com). The total transaction value of Chinese P2P lending platform in 2019 was $¥ 96.49$ billion. The operating return of the general platform approximately equals 0.5 to 1 percent of the transaction value. That is, the average unit revenue of the normal operation of each platform is $¥ 742,345 \sim 1,484,690$. In order to facilitate the calculation, the normal returns from compliance operation of the $\mathrm{P} 2 \mathrm{P}$ lending platform are scaled down by $1 / 100,000$ and are denoted by $R \in[7.4,14.8]$. Assume that the extra revenue gained by the platform through noncompliant operations accounts for 50 percent of normal operating returns, and the extra revenue of P2P lending platforms through noncompliant operation is set to $\Delta R \epsilon$ $[3.7,7.4]$. Besides, due to frequent "thunderstorm incidents" of the P2P lending platforms in 2019, the unit loss of investors’ investment was $¥ 10,000 \sim 50,000$. We can regard these losses as social damage caused by previous general supervision. The damage caused by the general supervision of regulatory authorities is scaled down by $1 / 100,000$ and is located at interval $[0.10,0.50](E \in[0.10,0.50])$. According to Pang et al. [22], a medium-sized P2P lending platform pays $¥ 2$ million for the normal operation costs (e.g., website construction cost, operating cost, and customer acquisition cost per year), assuming that the repayment incentives for borrowers paid by platforms account for $5 \sim 25$ percent of the normal cost, (e.g., $¥ 100,000 \sim 500,000$ ). The positive incentives for $\mathrm{P} 2 \mathrm{P}$ borrowers' repayment are scaled down by $1 / 100,000$ and are denoted by $V \in[1,5]$. The defaulting opportunity cost of P2P borrowers is set to $D \in[0.5,1.8]$.

According to the notice about penalties for the P2Prelated illegal platforms, most of the punishments located at interval from 10,000 to 50,000 yuan. For instance, Shenzhen Jinhai loan financial service company was fined $¥ 12,000$. China Anhui Juyun Technology Co., Ltd. was suspected of violating the regulations and was imposed an administrative penalty of $¥ 40,000$. Based on the previously mentioned information, it is assumed that the unit cost of general supervision by the regulatory authorities is between 10,000 and 50,000 yuan. The unit cost of strict supervision by the regulatory authorities is 60,000 to 100,000 yuan. They are scaled down by $1 / 100,000$ and are bounded to $C_{1} \in[0.60,1]$, $C_{2} \in[0.10,0.50]$. Since the supervision of P2P lending platforms is enhanced by the regulatory authorities after 2018, the reward coefficient and punishment coefficient of the regulatory authorities for $\mathrm{P} 2 \mathrm{P}$ lending platforms are at interval $[0.17,0.61](w \in[0.17,0.61])$ and $[0.34,0.91]$ $(\theta \in[0.34,0.91])$. In Figures $6-10, x(0), y(0)$, and $z(0)$ indicate the initial proportion of strict supervision, compliance operations, and repayment.

Figure 6 shows the numerical analysis, which concerns the impact of the initial population ratio of the $\mathrm{P} 2 \mathrm{P}$ lending participants' strategy selections on the evolutionary results. In Figure 6, it is obvious that the evolutionary equilibrium results of regulatory authorities, $\mathrm{P} 2 \mathrm{P}$ lending platforms, and borrowers are mutually influential. The convergence results of the three P2P lending participants are not only related to the initial proportion of their groups choosing behavioural strategies, but they are also affected by the behavioural strategies made by other participants. The probability of behavioural strategies chosen by the participants exhibits periodicity, either converging to 0 or tending to 1 . At the end, the three P2P lending participants do not reach a fixed equilibrium state. This shows that the strategic game among the regulatory authorities, P2P lending platforms, and borrowers has no evolutionary equilibrium strategy.

Figure 7 shows the three P2P lending participants choose different strategies in different initial states. In Figure 7, the evolutionary results of the three P2P lending participants only consider the impact of the initial state of behavioural strategy of each participant, whereas the mutual influence of the three participants is not considered. In Figure 7(a), $x(0)=0.2, y(0)=0.7$, and $z(0)=0.5$, in Figure $7(\mathrm{~b}), x(0)=0.1$, $y(0)=0.5$, and $z(0)=0.3$, in Figure $7(\mathrm{c}), x(0)=0.6, y(0)=0.7$, and $z(0)=0.3$, and in Figure $7(\mathrm{~d}), x(0)=0.7, y(0)=0.7$, and $z(0)=0.3$. From Figures $7(\mathrm{a})$ and $7(\mathrm{~b})$, we can conclude that when the supervision is lacking or the initial proportion of regulatory authorities adopting "strict supervision" strategy is low in the early stage of P2P lending industry, the behavioural strategies of P2P lending platforms and borrowers will evolve towards "noncompliant operation" and "default." It increases the operational risk to the P2P lending platforms [12]. In spite of the fact that the regulatory authorities are pushing for regulatory pressures later, P2P lending platforms and borrowers would not change the initial behavioural strategy due to the less regulatory pressure before. On the contrary, as shown in Figure 7(c), when the initial proportion of regulatory authorities adopting "strict supervision" strategy is high in the early stage of P2P lending industry, P2P lending platforms and borrowers will be subject to greater regulatory pressure, and the behavioural strategies of P2P lending platforms and borrowers will evolve towards "compliant operation" and "repayment." In Figure $7(d)$, it denotes that when regulatory pressure becomes a normal state, even after regulatory authorities adopt deregulation, P2P lending platforms and borrowers will follow the strategies of "compliant operation" and "repayment." Therefore, the strict supervision is necessary in the early stage of the P2P lending industry. Such a viewpoint is also supported by Shao and Bo [45] and Wang et al. [46].

Figure 8 shows the impact of changes in the costs of strict supervision and the damage caused by general supervision on the evolutionary result of regulatory authorities' strategy selection. In Figure 8, we changed the values of parameters $C_{1}$ and $E$. In Figure $8(\mathrm{a}), C_{1}=1$, and $E=0.1$, and in Figure $8(\mathrm{~b}), C_{1}=0.6$, and $E=0.5$. It can be seen from Figure 8 that when the initial proportion of behavioural strategies of $\mathrm{P} 2 \mathrm{P}$ lending participants is the same, the final evolutionary result of regulatory authorities can be changed by changing $C_{1}$ and $E$. In detail, in Figure 8(a), regulatory authorities choose the "general supervision" strategy, P2P lending platforms and borrowers choose "noncompliant operation" and "default" strategies, respectively. In Figure 8(b), the initial proportion of the participants' behavioural strategies remains unchanged. When the costs of strict supervision dropped from 1.0 to 0.6 , and the damage caused by general 


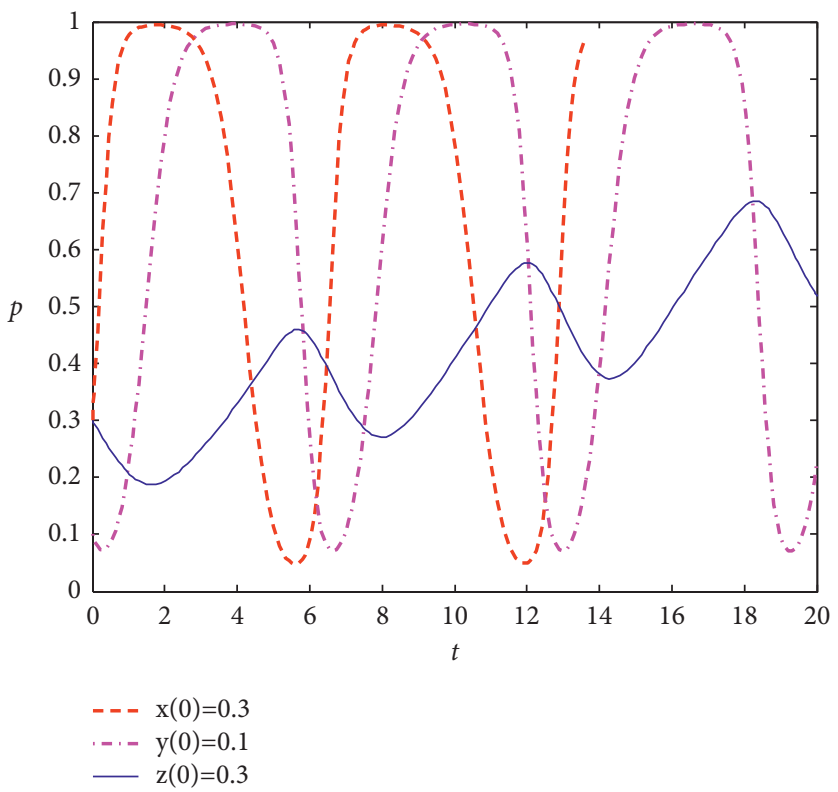

FIgURE 6: Evolutionary equilibrium results under different initial states.
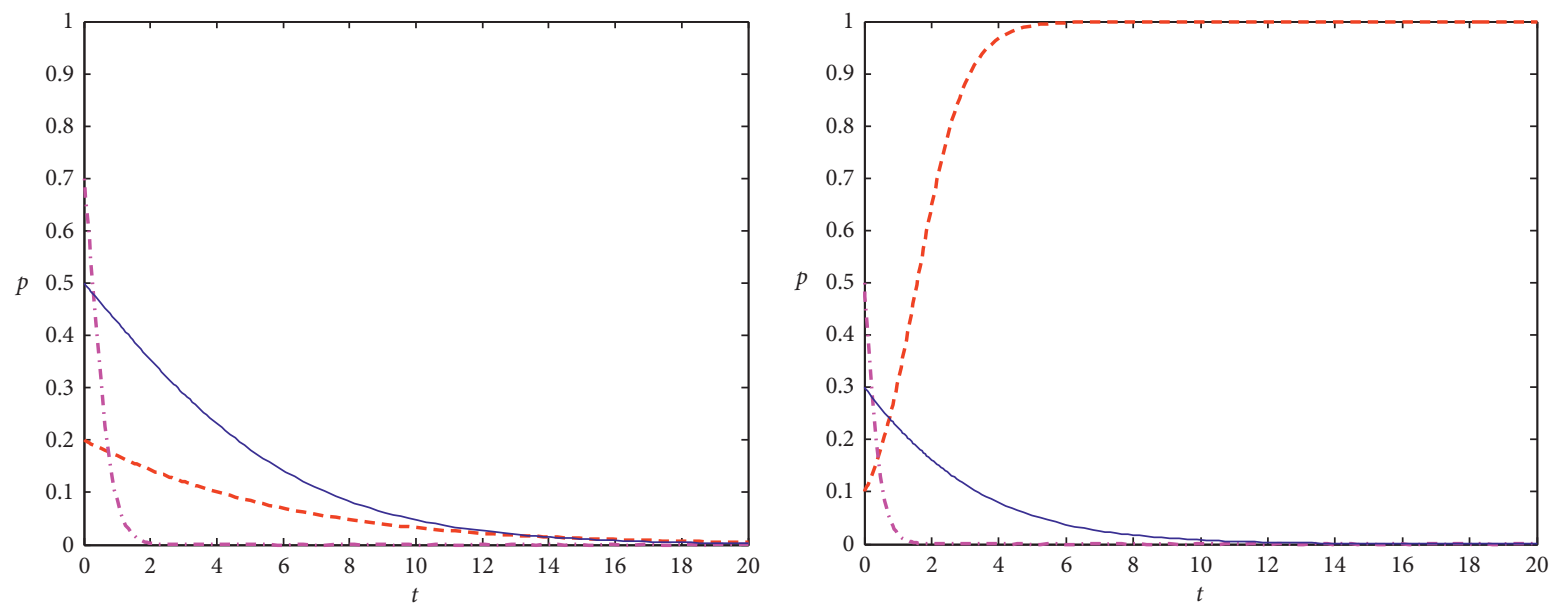

- - - $\mathrm{x}(0)=0.2$

- - $\quad x(0)=0.1$

- . . - $y(0)=0.7$

- - $\mathrm{y}(0)=0.5$

$\mathrm{z}(0)=0.5$

$\mathrm{z}(0)=0.3$

(a)

(b)

Figure 7: Continued. 


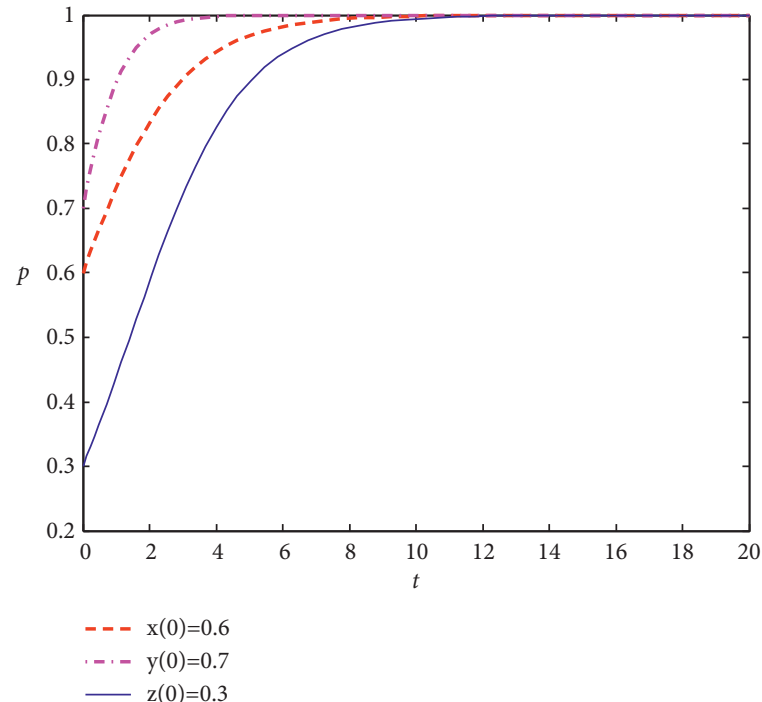

(c)

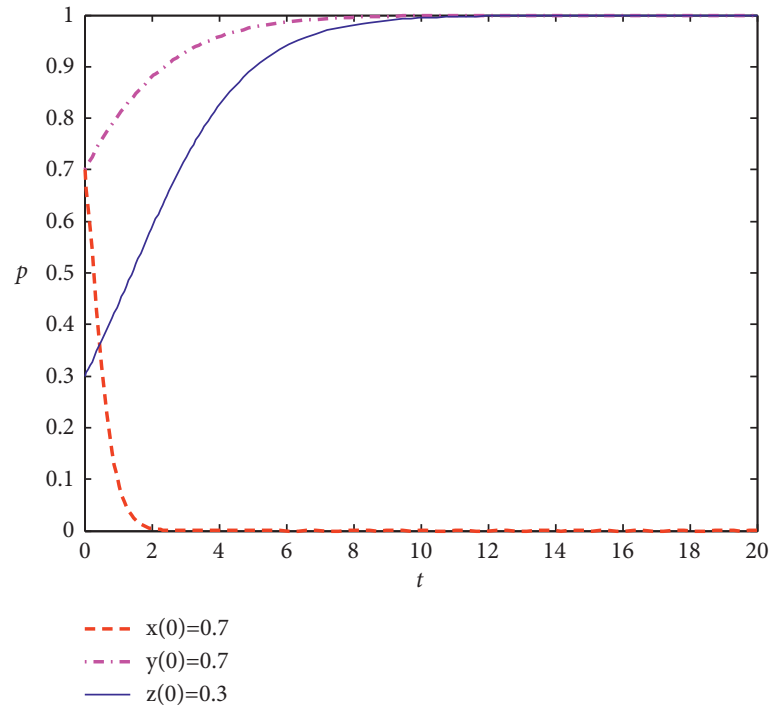

(d)

FiguRE 7: Strategy choices under different initial states. (a) $x(0)=0.2, y(0)=0.7$, and $z(0)=0.5$. (b) $x(0)=0.1, y(0)=0.5$, and $z(0)=0.3$. (c) $x(0)=0.6, y(0)=0.7$, and $z(0)=0.3$. (d) $x(0)=0.7, y(0)=0.7$, and $z(0)=0.3$.

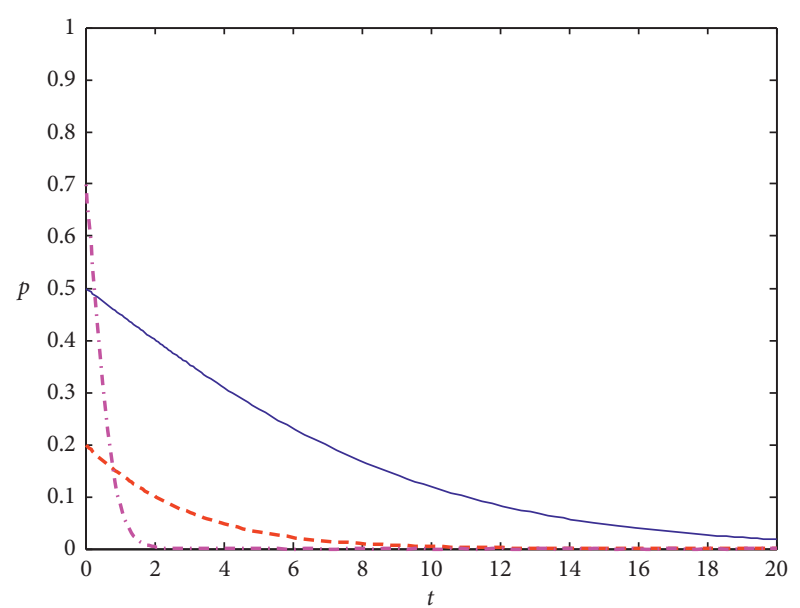

$$
\begin{array}{r}
-\mathrm{x}(0)=0.2 \\
-\mathrm{y}(0)=0.7 \\
\mathrm{z}(0)=0.5
\end{array}
$$

(a)

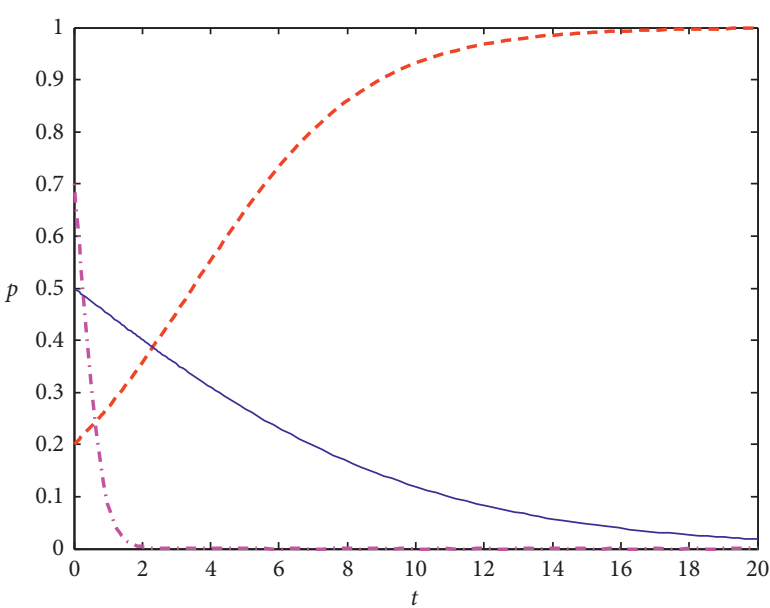

$$
\begin{array}{r}
--\mathrm{x}(0)=0.2 \\
-\because \mathrm{y}(0)=0.7 \\
-\mathrm{z}(0)=0.5
\end{array}
$$

(b)

Figure 8: The impact of the costs of strict supervision and the damage caused by general supervision on evolutionary results. (a) $C_{1}=1$, and $E=0.1$. (b) $C_{1}=0.6$, and $E=0.5$.

supervision increases from 0.1 to 0.5 , the behavioural strategy of regulatory authorities change from "general supervision" to "strict supervision" strategy, which is caused by $\theta(R+\Delta R)+C_{2}+E-C_{1}>0$. This result is in line with Proposition 2 and is supported by Pang et al. [22]. It denotes that through reducing the costs of strict supervision and increasing the damage caused by general supervision, regulatory authorities will eventually tend to the strategy of "strict supervision."

Figure 9 shows the impact of changes in regulatory authorities' rewards and penalties for $\mathrm{P} 2 \mathrm{P}$ platforms on the evolutionary result of P2P lending platforms' strategy selection. In Figure 9, while other parameters remain unchanged, we changed the values of parameters $w$ and $\theta$ and assessed the impact of changes of parameters $w$ and $\theta$ on the evolutionary results of the behavioural strategies of P2P lending platforms. In Figure 9(a), $w=0.2$, and $\theta=0.4$, and in Figure 9 (b), $w=0.4$, and $\theta=0.8$. It can be seen from Figure 9 that when the initial proportion of behavioural strategies of P2P lending participants is the same, by changing $w$ and $\theta$, the final evolutionary result of $\mathrm{P} 2 \mathrm{P}$ lending platforms can be changed. More specifically, in Figure 9(a), regulatory 

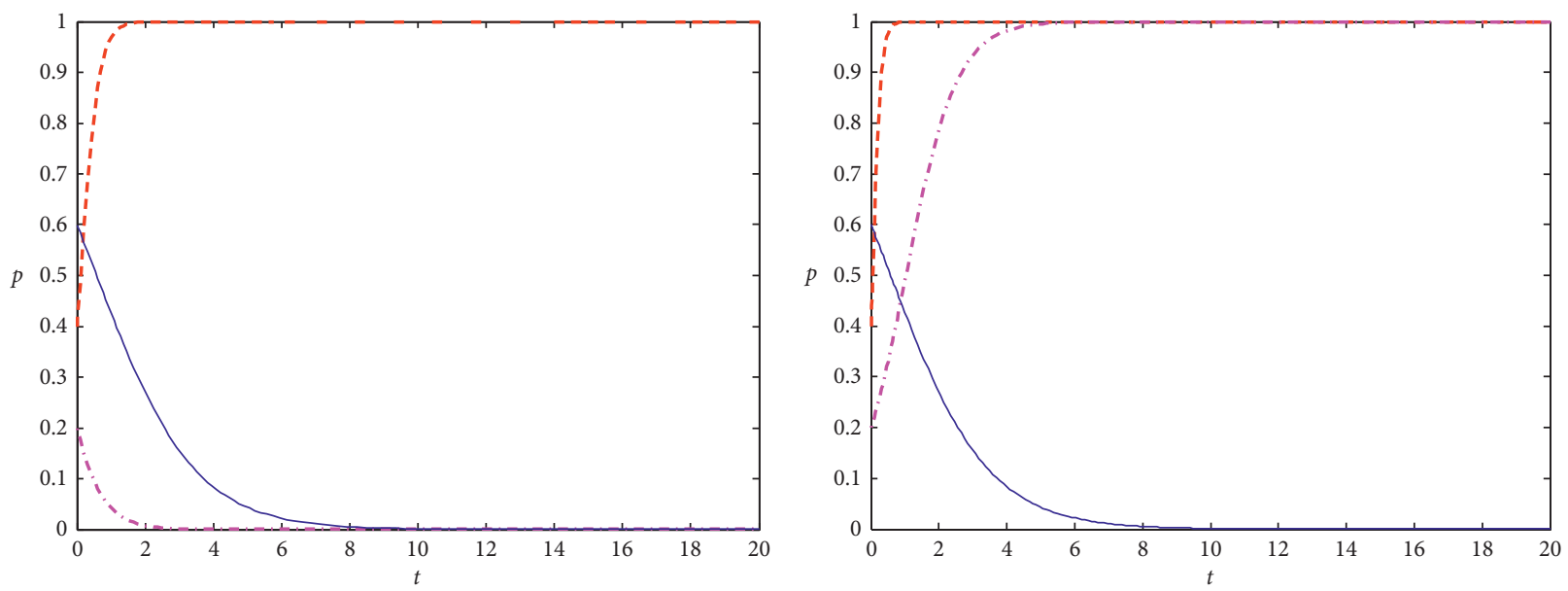

$\mathrm{x}(0)=0.4$
$-\mathrm{y}(0)=0.2$
$\mathrm{z}(0)=0.6$

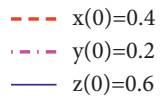

(a)

(b)

FIGURE 9: The impact of regulatory authorities' rewards and penalties for P2P lending platforms on the evolutionary result. (a) $w=0.2$, and $\theta=0.4$. (b) $w=0.4$, and $\theta=0.8$.

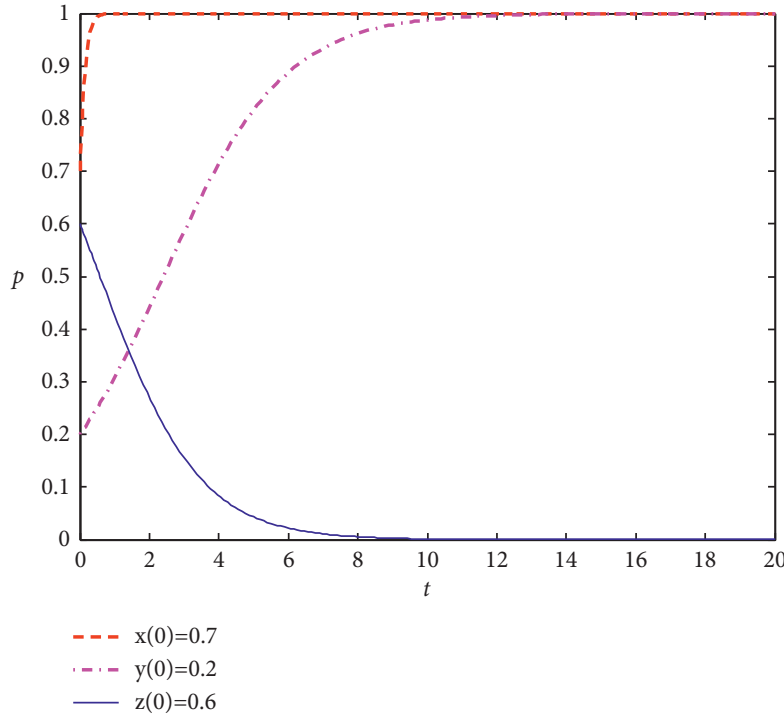

(a)

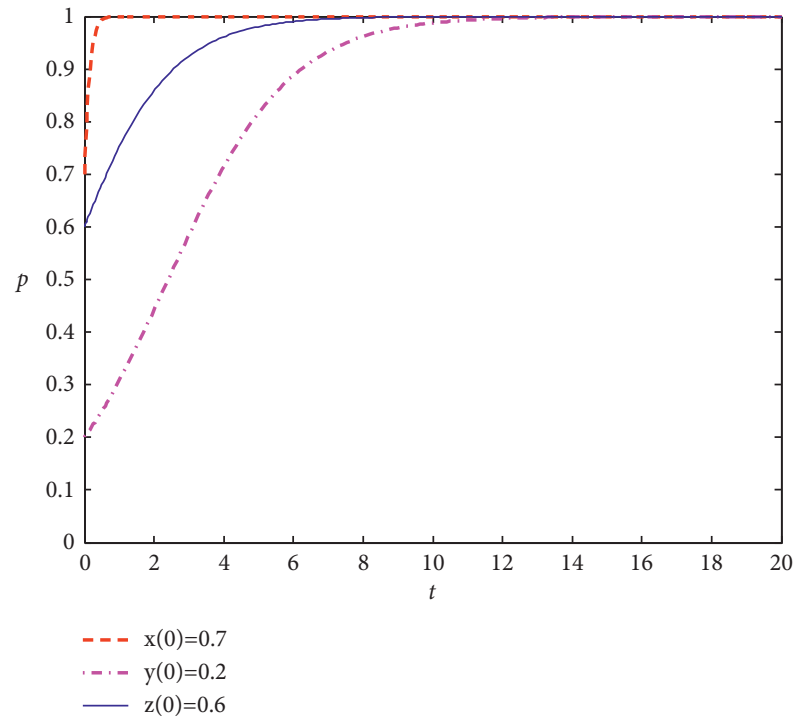

(b)

FIGURE 10: The impact of repayment incentives and defaulting opportunity costs on evolutionary results. (a) $V=1$, and $D=0.8$. (b) $V=4$, and $D=1.6$.

authorities choose the "strict supervision" strategy, and P2P lending platforms and borrowers choose "noncompliant operation" and "default" strategies, respectively. In Figure 9(b), the initial proportion of the participants' behavioural strategies remains unchanged. When regulatory authorities increase P2P lending platform rewards and penalties coefficients by a factor of two, the evolutionary results of regulatory authorities and borrowers remain unchanged, which makes $(1-\theta) \Delta R<(w+\theta) R$, and the behavioural strategy of $\mathrm{P} 2 \mathrm{P}$ lending platforms change from "noncompliant operation" to "compliant operation" strategy. This result is in line with Proposition 4. It denotes that through increasing rewards and penalties for P2P lending platforms, the benefit of compliant P2P lending platforms increases, the return of noncompliant P2P lending platforms decrease, and P2P lending platforms will eventually tend to the strategy of "compliant operation." In other words, increasing the rewards and penalties for the platform can improve the self-discipline of platform operations. Zhang and Wang show a better support for such a viewpoint [12]. 
Figure 10 shows the impact of changes in the repayment incentive given by the compliant $\mathrm{P} 2 \mathrm{P}$ lending platforms and the opportunity costs of the borrowers' default on the evolutionary result of borrowers' strategy selection. In Figure 10, with other parameters being unchanged, we change the values of parameters $V$ and $D$. In Figure 10(a), $V=1$, and $D=0.8$, and in Figure $10(\mathrm{~b})$, and $V=4, D=1.6$. Then, it can be seen from Figure 10 that when the initial group proportion of behavioural strategies of the three participants is the same, by changing $V$ and $D$, the evolutionary result of behavioural strategies of P2P borrowers can be changed. In Figure 10(a), regulatory authorities, P2P lending platforms, and borrowers choose "strict supervision," "compliant operation," and "default" strategies, respectively. In Figure 10(b), the initial proportion of the behavioural strategies of the three participants remains unchanged. When the compliant P2P lending platforms increase the repayment incentives of borrowers by a factor of four, and the defaulting opportunity cost of borrowers increases by two times, and the behavioural strategies of borrowers would change from "default" to "repayment" strategy, which is caused by $V+D>2 H$. This result corresponds to Proposition 6. It indicates that when the P2P lending platforms increase the repayment incentives and defaulting opportunity costs of borrowers, the cost of borrowers choosing "default" strategy will increase. Because the repayment incentives increase, the revenue of borrowers choosing "repayment" strategy will also increase, so borrowers will eventually choose the "repayment" strategy. Brihaye et al. [23] and Pang et al. [47] showed a better support for such results mentioned onwards.

\section{Conclusions and Implications for Future Research}

We have discussed the interaction and cooperation among $\mathrm{P} 2 \mathrm{P}$ lending participants from the sustainable perspective. Conflicts of interest among the regulatory authorities, P2P lending platforms, and borrowers are analysed. Afterwards, the evolutionary trends of the three participants' behavioural strategies are analysed using an evolutionary game model of three players. Finally, the impacts of relevant factors on the evolutionary result of behavioural strategies of participants are investigated. The conclusions are shown as follows.

(1) The strict supervision of the P2P lending platform is necessary for the sustainable operation of the platform in the short term. According to the numerical analysis, there are significant differences in the results of the game of three players with different initial states. It is denoted that the P2P lending platforms and borrowers will choose the "noncompliant operation" and "default" strategies when the regulatory system is insufficient in the early stage of the P2P lending industry. Even after the regulatory authorities strengthen their regulatory intensity, the P2P lending platforms and borrowers will also choose the "noncompliant operation" and "default" strategies. On the contrary, when intense supervision is imposed in the early stage and regulatory pressure by regulatory authorities becomes a normal state, even if there is a lack of regulation in the future, the P2P lending platforms and borrowers will still actively choose the "compliant operation" and the "repayment" strategies.

(2) Given the conflict of interest among regulatory authorities, the P2P lending platforms and the borrowers (e.g., the platform operating incompliance for the extra income damages the interests of the regulatory authorities [22]), the interests of the three participants can be transformed into revenues and costs to formulate an EGM. The replicator dynamics equation is used to solve the equilibrium solution of the EGM. The behavioural strategies of the three participants can be changed into strict supervision, compliant operation, and repayment to balance the interests of the participants by adjusting the parameters (e.g., $C_{1}, E, w, \theta, V$, and $D$ ).

(3) Through reducing the costs of strict supervision and increasing the damage caused by general supervision, regulatory authorities will eventually choose the "strict supervision" strategy. By increasing the incentives and penalties for the P2P lending platforms, the P2P lending platforms will eventually choose the "compliant operation" strategy. Meanwhile, when the $\mathrm{P} 2 \mathrm{P}$ lending platforms increase the repayment incentives and the defaulting opportunity costs of borrowing, then, borrowers will eventually choose the "repayment" strategy.

The conclusions of this study have an important practical significance for the sustainable development of the P2P lending industry in China. In detail, when P2P lending emerged in China, the risks in the industry (e.g., absconding with the money and fraudulent risks) soared due to the lack of regulations of this industry [48]. As such, a series of policies have begun to be issued to gradually stabilize the P2P lending industry since 2016 [22]. Throughout the past three years, Chinese regulatory authorities raised the threshold to the entry of P2P lending platforms, the noncompliant platforms were gradually eliminated, and the standardization of the P2P lending industry has improved [12]. In fact, this confirms the necessity of strict supervision by regulatory authorities in the early stage of the P2P lending industry. In addition to the regulatory measures, the support policies (e.g., financial support and priority projects) should be adopted to encourage the compliant P2P lending platforms to ensure the competitive advantages. Meanwhile, penalties for illegal platforms should be increased to further eliminate the noncompliant $\mathrm{P} 2 \mathrm{P}$ platforms. When most of platforms can operate in compliance, the regulatory intensity can be appropriately reduced. Moreover, it is necessary to improve the credit system of the individuals and enterprises. A public credit information service platform should be established and improved, to provide centralized inquiry services for the whole society. It plays the role of credit restraint to encourage the $\mathrm{P} 2 \mathrm{P}$ lending platforms and borrowers to keep trustworthy. 
This study provides several insights on the behavioural theory of the P2P lending participants regarding sustainable operation. First, a theoretical link between sustainable principle and behaviour of $\mathrm{P} 2 \mathrm{P}$ lending participants is proposed to balance the interests of the participants. Second, this paper aims to design an interest-coordination mechanism among P2P lending participants to guide each participant to choose the behavioural strategy, which is beneficial to the sustainability of P2P lending. Third, meaningful suggestions are provided for regulatory authorities' regulation of $\mathrm{P} 2 \mathrm{P}$ lending industry, which not only ensure the sustainable development of P2P lending industry but also provide insights for the supervision of other emerging industries (e.g., electronic currency).

This study can be further extended. First, in order to prevent $\mathrm{P} 2 \mathrm{P}$ borrowers from defaulting, most of P2P lending platforms began to establish an information disclosure system of borrowers and use this system to construct the defaulting punishment of borrowers. Thus, the penalty of default based on the information disclosure can be used as an influencing factor to add to the three-player EGM. Besides, the altruistic preference behaviour has an important impact on the decision-making of multiparticipants system and can be used as an adjustment tool to achieve system coordination $[49,50]$. Therefore, the altruistic preference behaviour can be introduced into the interest-coordination mechanism among P2P lending participants for the sustainability of P2P lending. Finally, this paper, considers only the three participants, including regulatory authorities, P2P lending platforms, and borrowers, but the investors are indispensable in the $\mathrm{P} 2 \mathrm{P}$ lending process. Investors will be unable to introduce and extend the three-player EGM to the four-player EGM.

\section{Data Availability}

The data used to support the findings of this study are included within the article.

\section{Conflicts of Interest}

The authors declare no conflicts of interest.

\section{Acknowledgments}

This research was supported by the Scientific Research StartUp Foundation for Introduction of Advanced Talents in Hunan Institute of Technology grant no. HQ19004 and the Scientific Research of Nanfang College Guangzhou grant no. $2020 X K 02$.

\section{References}

[1] H. Zhao, Y. Ge, Q. Liu, G. Wang, E. Chen, and H. Zhang, "P2P lending survey: platforms, recent advances and prospects," ACM Transactions on Intelligent Systems \& Technology, vol. 86, p. 1, 28.

[2] C. You, "Recent development of FinTech regulation in China: a focus on the new regulatory regime for the P2P lending (loan-based crowdfunding) market," Capital Markets Law Journal, vol. 13, no. 1, pp. 85-115, 2017.

[3] B. Niu, J. Ren, A. Zhao, and X. Li, "Lender trust on the P2P lending: analysis based on sentiment analysis of comment text," Sustainability, vol. 12, no. 8, p. 3293, 2020.

[4] B. Wang, Z. Ding, X. Wang, and K. Shi, "Crosscorrelation analysis between P2P lending market and stock market in China," Mathematical Problems in Engineering, vol. 2020, Article ID 7134172, 9 pages, 2020.

[5] A. Bachmann, A. Becker, D. Buerckner, and M. Hilker, "Online peer-to-peer lending-a literature review," Journal of Internet Banking and Commerce, vol. 16, no. 2, pp. 1-18, 2011.

[6] H. Wang, K. Chen, W. Zhu, and Z. X. Song, "A process model on P2P lending," Financial Innovation, vol. 1, no. 3, pp. 1-8, 2015.

[7] I. García-Pérez, M.-J. Muñoz-Torres, and M.-Á. FernándezIzquierdo, "Microfinance literature: a sustainability level perspective survey," Journal of Cleaner Production, vol. 142, no. 4, pp. 3382-3395, 2017.

[8] C. Cao, Y. Liu, O. Tang, and X. Gao, "A fuzzy bi-level optimization model for multi-period post-disaster relief distribution in sustainable humanitarian supply chains," International Journal of Production Economics, vol. 235, Article ID 108081, 2021.

[9] H. M. Haugh and A. Talwar, "How do corporations embed sustainability across the organization?" Academy of Management Learning \& Education, vol. 9, no. 3, pp. 384-396, 2010.

[10] H. Chen and C. H. Tsai, "Changing regulations of peer-topeer lending in China," Banking \& Financial Services Policy Report, vol. 36, no. 11, pp. 13-25, 2017.

[11] S. Hsu, J. Li, and H. Bao, "P2P lending in China: role and prospects for the future," The Manchester School, 2020, In press.

[12] N. Zhang and W. Wang, "Research on balance strategy of supervision and incentive of $\mathrm{P} 2 \mathrm{P}$ lending platform," Emerging Markets Finance and Trade, vol. 55, no. 13, pp. 3039-3057, 2019.

[13] D. Liu, D. Brass, D. J. Brass, Y. Lu, and D. Chen, "Friendship in online peer-to-peer lending: pipes, prisms, and relational herding," Management Information Systems Quarterly, vol. 39, no. 3, pp. 729-742, 2015.

[14] E. Lee and B. Lee, "Herding behavior in online P2P lending: an empirical investigation," Electronic Commerce Research and Applications, vol. 11, no. 5, pp. 495-503, 2012.

[15] K. Zhang and X. Chen, "Herding in a P2P lending market: rational inference OR irrational trust?" Electronic Commerce Research and Applications, vol. 23, pp. 45-53, 2017.

[16] J. Ding, J. Huang, Y. Li, and M. Meng, "Is there an effective reputation mechanism in peer-to-peer lending? Evidence from China," Finance Research Letters, vol. 30, pp. 208-215, 2019.

[17] R. Ge, J. Feng, and B. Gu, "Borrower's default and self-disclosure of social media information in P2P lending," Financial Innovation, vol. 2, no. 1, p. 30, 2016.

[18] K. L. Lo, J. J. Mi, M. Yang, and S. Zhang, "Do financial regulations have impacts on ownership structure of $\mathrm{P} 2 \mathrm{P}$ firms?" Applied Economics Letters, vol. 27, no. 14, pp. 1156-1159, 2020.

[19] Z. Wei and M. Lin, "Market mechanisms in online peer-topeer lending," Management Science, vol. 63, no. 11, pp. 4236-4257, 2016.

[20] W. Liu and L. Q. Xia, "An evolutionary behavior forecasting model for online lenders and borrowers in peer-to-peer 
lending," Asia-Pacific Journal of Operational Research, vol. 34, no. 1, Article ID 1740008, 2017.

[21] R. Rezagharehbagh, A. Hafezalkotob, A. Makui, and A. Zhang, "Peer-to-peer financing choice of SME entrepreneurs in the re-emergence of supply chain localization," International Transactions in Operational Research, vol. 27, no. 5, pp. 2534-2558, 2019.

[22] S. Pang, J. Yang, R. Li, and J. Cao, "Static game models and applications based on market supervision and compliance management of P2P platform," Mathematical Problems in Engineering, vol. 2020, Article ID 8869132, 17 pages, 2020.

[23] T. Brihaye, J. D. Pril, M. Labie, and A. Périlleux, "Positive versus negative incentives for loan repayment in microfinance: a game theory approach," Review of Development Economics, vol. 23, no. 2, pp. 577-597, 2019.

[24] S. Johnson, A. Ashta, and D. Assadi, "Online or offline?: the rise of peer-to-peer lending in microfinance," Journal of Electronic Commerce in Organizations, vol. 8, no. 2, pp. 26-37, 2010.

[25] M. Lin, N. R. Prabhala, and S. Viswanathan, "Judging borrowers by the company they keep: friendship networks and information asymmetry in online peer-to-peer lending," Management Science, vol. 59, no. 1, pp. 17-35, 2013.

[26] E. Berkovich, "Search and herding effects in peer-to-peer lending: evidence from prosper.com," Annals of Finance, vol. 7, no. 3, pp. 389-405, 2011.

[27] M. Herzenstein, U. M. Dholakia, R. L. Andrews et al., "Strategic herding behavior in peer-to-peer loan auctions," Journal of Interactive Marketing, vol. 25, no. 1, pp. 27-36, 2011.

[28] C. Jiang, Q. Xu, W. Zhang, M. Li, and S. Yang, "Does automatic bidding mechanism affect herding behavior? Evidence from online P2P lending in China," Journal of Behavioral and Experimental Finance, vol. 20, pp. 39-44, 2018.

[29] D. Kim, "The importance of detailed patterns of herding behaviour in a P2P lending market," Applied Economics Letters, vol. 27, no. 2, pp. 127-130, 2020.

[30] X. Yang, W. Fan, and S. Yang, "Identifying the influencing factors on investors' investment behavior: an empirical study focusing on the Chinese P2P lending market," Sustainability, vol. 12 , no. 13 , p. $5345,2020$.

[31] N. Du, L. Li, T. Lu, and X. H. Lu, "Prosocial compliance in P2P lending: a natural field experiment," Management Science, vol. 22, no. 12, pp. 1-19, 2019.

[32] T. Yu and W. Shen, "Funds sharing regulation in the context of the sharing economy: understanding the logic of China's P2P lending regulation," Computer Law \& Security Report, vol. 35, no. 1, pp. 42-58, 2019.

[33] M. Cohen and A. Sundararajan, "Self-regulation and innovation in the peer-to-peer sharing economy," University of Chicago Law Review Dialogue, vol. 82, no. 7, pp. 116-133, 2015.

[34] F. Wei and W. Chan, "The cooperative stability evolutionary game analysis of the military-civilian collaborative innovation for China's satellite industry," Mathematical Problems in Engineering, vol. 2019, Article ID 3938716, 17 pages, 2019.

[35] X. Yue and Y. Lin, "Effectiveness of punishment and operating subsidy in supervision of China's pension PPP projects: an evolutionary game and simulation analysis," Mathematical Problems in Engineering, vol. 2019, Article ID 9641429, 12 pages, 2019.

[36] A. Antoci, R. Dei, and M. Galeotti, "Financing the adoption of environment preserving technologies via innovative financial instruments: an evolutionary game approach," Nonlinear
Analysis: Theory, Methods \& Applications, vol. 71, no. 12, pp. e952-e959, 2009.

[37] Y. Zhao, D. Li, and L. Pan, "Cooperation or competition: an evolutionary game study between commercial banks and big data-based E-commerce financial institutions in China," Discrete Dynamics in Nature and Society, vol. 2015, Article ID 890972, 8 pages, 2015.

[38] C. Zhang, R. Pan, A. Chaudhury, and C. X. Xu, "Effect of security investment on evolutionary games," Journal of Information Science and Engineering, vol. 30, no. 6, pp. 16951718, 2014.

[39] Z. Li, G. Jin, and S. Duan, "Evolutionary game dynamics for financial risk decision-making in global supply chain," Complexity, vol. 2018, Article ID 9034658, 10 pages, 2018.

[40] Y. Yang and C. Fu, "Inclusive financial development and multidimensional poverty reduction: an empirical assessment from rural China," Sustainability, vol. 11, no. 7, pp. 1-17, 2019.

[41] J. Galak, D. Small, and A. T. Stephen, "Microfinance decision making: a field study of prosocial lending," Journal of Marketing Research, vol. 48, pp. S130-S137, 2011.

[42] G. Burtch, A. Ghose, and S. Wattal, "Cultural differences and geography as determinants of online pro-social lending," Management Information Systems Quarterly, vol. 38, no. 3, pp. 773-794, 2013.

[43] X. Chen, X. Hu, and S. Ben, "How do reputation, structure design and FinTech ecosystem affect the net cash inflow of P2P lending platforms? Evidence from China," Electronic Commerce Research, 2020, In press.

[44] C. Li, F. Zhang, C. Cao, Y. Liu, and T. Qu, "Organizational coordination in sustainable humanitarian supply chain: an evolutionary game approach," Journal of Cleaner Production, vol. 219, pp. 291-303, 2019.

[45] S. Shao and H. Bo, "Behavioural aspects of China's P2P lending," The European Journal of Finance, pp. 1-16, 2021, In press.

[46] Y. Wang, X. Han, Y. Li, and F. Liu, "Efficiency and effect of regulatory policies on the online peer-to-peer (P2P) lending industry," Emerging Markets Finance and Trade, pp. 1-14, 2021, In press.

[47] S. Pang, H. Xian, and R. Li, "A default penalty model based on C2VP2C mode for internet financial platforms in Chinese market," Electronic Commerce Research, 2020, In press.

[48] L. Ma, Y. Wang, C. Ren, H. Li, and Y. Li, "Early warning for internet finance industry risk: an empirical investigation of the P2P companies in the coastal regions of China," Journal of Coastal Research, vol. 106, pp. 295-299, 2020.

[49] Y. Wang, Z. Yu, M. Jin, and J. Mao, "Decisions and coordination of retailer-led low-carbon supply chain under altruistic preference," European Journal of Operational Research, vol. 293, no. 3, pp. 910-925, 2021.

[50] Y. Wang, R. Fan, L. Shen, and W. Miller, "Recycling decisions of low-carbon E-commerce closed-loop supply chain under government subsidy mechanism and altruistic preference," Journal of Cleaner Production, vol. 259, Article ID 120883, 2020. 